\title{
Compositional analysis of seasonal variation in Danish residual household waste
}

\author{
Edjabou, Maklawe Essonanawe; Boldrin, Alessio; Astrup, Thomas Fruergaard
}

Published in:

Resources, Conservation and Recycling

Link to article, DOI:

10.1016/j.resconrec.2017.11.013

Publication date:

2018

Document Version

Peer reviewed version

Link back to DTU Orbit

Citation (APA):

Edjabou, M. E., Boldrin, A., \& Astrup, T. F. (2018). Compositional analysis of seasonal variation in Danish residual household waste. Resources, Conservation and Recycling, 130, 70-79.

https://doi.org/10.1016/j.resconrec.2017.11.013

\section{General rights}

Copyright and moral rights for the publications made accessible in the public portal are retained by the authors and/or other copyright owners and it is a condition of accessing publications that users recognise and abide by the legal requirements associated with these rights.

- Users may download and print one copy of any publication from the public portal for the purpose of private study or research.

- You may not further distribute the material or use it for any profit-making activity or commercial gain

- You may freely distribute the URL identifying the publication in the public portal

If you believe that this document breaches copyright please contact us providing details, and we will remove access to the work immediately and investigate your claim. 
Paper is published in Resources, Conservation \& Recycling

\section{Compositional analysis of seasonal variation in Danish} residual household waste

1

2

3

4

5

6

7

8

9

10

11

12

13

14

15

16

17
*) Corresponding author: vine@env.dtu.dk;

Phone number: +45 45251498 


\section{Abstract}

19 Seasonal variations are considered one of the key factors affecting the generation and composition 20 of residual waste. Despite this importance, attempts have not been made to characterize residual 21 household waste consistently by accounting for seasonal variations in waste disposal patterns. To 22 assess differences between seasons and within individual households, we collected residual 23 household waste from the same 101 households in summer, autumn and winter. The waste bags

24 were sorted individually, and residual household waste data (mass and composition) were generated 25 for each household. In total, 3 tonnes of waste were collected, weighed and manually sorted into 26 nine (9) waste fractions. The result of mixed linear model indicated that for this study area, seasonal variations may introduce no significant difference to the mass and composition of residual household waste. However, residual waste generation within a household may change significantly between the seasons. The result also showed that while household size may significantly influence

30 the generation of residual household, the difference in residual household waste composition was 31 not significantly different between household sizes. 
33 Keywords

34 Seasonal variations

35 Isometric log-ratio

36 Waste composition and generation

37 Repeated measures

38 Multivariate mixed model

39 


\section{Introduction}

41 In several countries, the approach to managing waste is changing rapidly. In particular, the transition 42 of municipal solid waste management to circular economy and resource efficiency poses 43 unprecedented challenges in terms of waste management planning, which in turn typically requires 44 comprehensive and reliable data about waste generation and composition. Generally, these data are obtained from sampling, sorting and analysing solid waste streams into desired and pre-defined waste fractions (Edjabou et al., 2015a). To attain reliable data, the seven sampling errors described by Pierre Gy should be avoided: (1) long-range heterogeneity fluctuation, (2) periodic heterogeneity fluctuation, (3) fundamental errors, (4) grouping and segregation, (4) increment and delimitation, (5) increment extraction and (7) preparation errors (Pitard, 1993). Among these errors, tackling periodic heterogeneity fluctuations is particularly challenging, because repeated sampling and analysis is costly and time-consuming (Dahlén and Lagerkvist, 2008).

To address periodic variations (e.g. short-term and seasonal variations), available methods for the determination of waste composition recommend that a waste sample should: (1) cover at least one full week (including weekends), given that the waste generated during weekends may be different to weekdays (Edjabou et al., 2015a), and (2) be stratified based on seasons, which may induce significant variations in the generation and composition of residual household waste (European Commission, 2004). Generally, a full week's data for waste generation and composition are often assumed representative of the whole year (see Edjabou et al., 2015b; Riber et al., 2009). In contrast, a number of other studies have investigated the seasonal generation and composition of household waste (e.g. Denafas et al., 2014; Edjabou et al., 2012; Kamran et al., 2015; Andersen and Larsen, 2012, Aguilar-Virgen et al. 2013). Although these studies concluded that the generation and composition of household waste are affected by seasonal variation, a major drawback of these studies is that the waste was not sampled from the same households for all seasons, thereby introducing 
inherent uncertainty related to variations in the households' socio-economic situation.

Besides not addressing fluctuations properly, several of the previously mentioned studies did not deal accurately with the fact that waste composition datasets, by nature, are "closed datasets", i.e. the relative contribution of waste fractions should always sum up to $100 \%$ (Aitchison, 1986). A major problem with closed datasets is that parts of the composition are linked intrinsically to each other (Edjabou et al., 2015c). Consequently, an increase in the percentage of a waste fraction will lead automatically to a decrease in another fraction and vice versa. This natural property of compositional data biases statistical analysis of the relationship between seasonal variations and waste composition. Moreover, results from statistical analysis applied to dataset for waste fraction generation rates (kg waste fraction per week) can neither be necessary generalised nor extrapolated to waste fractional composition dataset (see Edjabou et al., 2017). As a solution, a procedure based on multivariate analysis applied to log-ratio coordinates has been suggested (e.g. Aitchison and $\mathrm{Ng}$, 2005; Egozcue et al., 2003). For this study, an isometric log-ratio transformation (Egozcue et al., 2003) was applied to the waste composition dataset (see SM Table 1), in order to overcome the total sum constraint problem (Aitchison, 1994). Another advantage of the isometric log-ratio transformation is that the same isometric log-ratio coordinates are obtained with either individual waste fraction generation rates ( $\mathrm{kg}$ waste per week for each waste fraction) or percentage compositions.

The objective of this study was to assess whether the generation and composition of residual household waste are associated with seasonal variations. This was achieved by: (i) collecting waste composition data from 101 households in Denmark, (ii) statistically treating the data using compositional data techniques and (iii) investigating and identifying any significant relationships between seasons and household size. 
 \\ 2 Methods and materials}

\subsection{Study area}

Residual household waste generated in a Copenhagen suburb was sampled and characterized. In this area, paper, board, metal, garden waste, hazardous waste, waste electrical and electronic equipment (WEEE) as well as bulky items were source-segregated. However, some of these fractions are often misplaced in the residual household bins. Thus, misplaced waste fractions are waste fractions that should have been source-sorted by households for recycling purposes. Therefore, residual household waste included food waste, miscellaneous combustible (e.g. diapers, textiles, etc.) plastic packaging and film, tissue paper, wrapping paper and misplaced source-segregated waste (Table 1).

In this study area, the waste bins had volumes of 180-360 1. They are equipped with a throwback lid, which is always closed to protect the waste from weather exposure (rain, snow, sun, etc.). Thus, the weather and seasonal variation cannot influence the physical characteristics of the waste during the storage and the collection from households. As result, any significant changes in generation and composition of waste can be attributed to the households.

\subsection{Experimental design}

The waste was sampled from the same group of households in autumn, summer and winter, in 20112012. Samples from individual households were taken from waste generated during a full week in each of the three seasons, in compliance with existing guidelines, such as European Commission (2004), Nordtest, (1995) and US EPA, (2002). The waste samples were retrieved as part of the ordinary waste collection schedule, to prevent any changes in household waste generation that may lead to biased results. Thus, the municipality department responsible for waste management selected the waste collection route in collaboration with the waste collection company in the study area. The households located in this collection route are assumed to be representative for the study area with regard to the volume of waste bins, household size and socio-economic patterns (e.g. population distribution) (see Edjabou et al.,2015). 
In total, 101 randomly selected households were involved in the study. An additional nine

113 households, initially part of the project, were discarded because they missed one or more sampling

114 campaigns. The exclusion was necessary to ensure it was possible to identify any changes in 115 composition and generation rates within individual houses. For each household, the number of 116 occupants for the three seasons was obtained from the local council authorities.

117 Residual household waste was collected prior to any compaction and sorted into (1) food waste 118 (Food), (2) gardening waste (Garden), (3) paper, (4) board, (5) metal, (6) plastic packaging, (7) 119 plastic films, (8) inert materials and (9) miscellaneous combustible waste (Table 1). Here, the paper 120 fraction included all types of paper, such as kitchen tissue, newsprints, etc. For this study, gardening 121 waste, paper, board, metal and plastic packaging are misplaced waste, whereas food waste, 122 miscellaneous combustible waste are residual household waste.

Waste sorting was conducted within a week after sampling. Neither sieving nor mass reduction

124

125

132

133

134 135 was applied prior to waste sorting. Furthermore, waste from individual households was sorted separately, and the data were then recorded and analysed.

The total amount of residual household waste sampled was 3 tonnes, corresponding to about 1 tonne per season (Table 2). The numbers of households as a function of household size (number of occupants per households) and per sampling period are provided in Table 2. For this study, households were split into four groups, according to the number of occupants, namely one person (1p), two persons (2p), three persons (3p) and more than three persons (4p+) (Edjabou et al., 2016).

\section{Table 1}

\section{Table 2}


136

137

138

139

140

141

142

143

144

145

146

147

148

149

150

151

152

153

154

155

156

\subsection{Statistical Analysis}

\subsubsection{Geometric mean bar plot}

We computed geometric mean of data for a fractional solid waste composition as follows:

$g_{m i}(x)=\exp \left[1 / n \sum_{i=1}^{D} \ln \left(x_{i}\right)\right]$

Eq. (1)

where $g_{m i}(x)$ is the geometric mean of a waste fraction $m$ for the individual subgroup $i$ (e.g. autumn, winter and summer), $n$ is the number of observations (e.g. 101 households) and $\ln \left(x_{i}\right)$ is the natural logarithm and its inverse $\exp \left(x_{i}\right)$.

To construct the geometric mean bar plot, we used the ratio at a logarithmic scale between geometric means as follows:

$\log \left(g_{m i}(x) / g_{i}(x)\right)=\boldsymbol{X}_{\boldsymbol{m}}$

Eq. (2)

where $g_{i}(x)$ is the geometric mean of waste fractions $m$ (e.g. food waste, gardening waste) without subgroups, and $\boldsymbol{X}_{\boldsymbol{m}}$ is the ratio at a logarithmic scale for the waste fraction $m$. Based on Eq. (2), geometric means $g_{m i}$ of a waste fraction for each subgroup can be compared consistently and illustrated graphically by means of a geometric mean bar plot. To interpret the bar plot, $\boldsymbol{X}_{\boldsymbol{m}}$ is backtransformed to a ratio of geometric means $\left(\mathrm{k}_{\mathrm{m}}\right)$ as follows:

$k_{m}=\exp \left(\boldsymbol{X}_{\boldsymbol{m}}\right)=\frac{g_{m i}(x)}{g_{i}(x)}$

Based on Eq.(3), three possible scenarios are apparent: (1) if $\boldsymbol{X}_{\boldsymbol{m}}>0$, then $k_{m}>1$ and $k_{m}$ $=1+r_{m}$. This corresponds to cases where bars are above the $\mathrm{x}$-axis line and is interpreted as the geometric mean $\left(g_{m i}\right)$ of a fraction $-m$ for a subgroup $i$ is $(r \%)$ higher than the average geometric mean $\left(g_{i}\right)$. (2) if $\boldsymbol{X}_{\boldsymbol{m}}<0$, then $k_{m}<1$, and $k_{m}=1-r_{m}$, which occurs in cases where bars are below the X-axis. Here, the geometric mean $\left(g_{m i}\right)$ is $(r \%)$ lower than the average geometric mean $\left(g_{i}\right)$. (3) if $\boldsymbol{X}_{\boldsymbol{m}}$ 
$157=0, k_{m}=1$ and $r_{m}=0$, thus $g_{i}=g_{m}$. This is shown by non-existent bars. Thus, small bars indicate a

158 small difference between subgroups, whereas large bars highlight major discrepancies.

159

160

161

162

163

164

165

166

167

168

169

170

171

172

173

174

175

176

177

178

179

\subsubsection{Mixed linear modelling}

For this study, the general mixed linear model has the form:

$Y_{i j k}=\mu+i_{i}+v_{j}+(i v)_{i j}+f_{k}+\epsilon_{i j k}$

where $\mu$ is a general constant, $i_{i}$ is the contribution of the season $i, v_{j}$ is the contribution made by household size $j$, (iv) $)_{i j}$ is the contribution of the interaction between season $i$, household size $j$, and $f_{k}$ is the contribution of a random effect $k$, and $Y_{i j k}$ is a dependent variation. For this study, $Y_{i j k}$ represents waste composition (in percentage) and generation rates $(\mathrm{kg} /$ household $/$ week and $\mathrm{kg} /$ person/week) and is known as "compositional data with a total" (Pawlowsky-glahn et al., 2015). Noticeably, $\mu, i_{i}, v_{j},(i v)_{i j}$ are fixed effects and $f_{k}$ is a random effect explaining the 'mixed linear model' term. Fixed effects analyse the influence of season and household size on the average waste composition and generation rates, whereas a random effect examines the variability in individual houses (Faraway, 2016; Schutz and Gessaroli, 1987). In this sense, it should also be noted that for the waste composition consisting of nine fractions, $Y_{i j k}$ is a compositional random variable (see van den Boogaart et al., 2014, for mathematical specifications and computation). Here, the waste generation rates were analysed in a separate linear mixed model (Kynčlová et al., 2015).

The critical assumption of the mixed linear model applied to the waste composition dataset and waste generation rates, namely (1) homogeneity of variances and covariance and (2) normality distribution of the residuals, were investigated respectively by a Box's M-test and squared Mahalanobis (Berridge and Crouchley, 2011; Faraway, 2016) and provided in the Supplementary data.

\subsubsection{Software}


181 language and software (R Core Team, 2017) and the freeware CoDaPack (Thió-Henestrosa and

182 Martín-Fernández, 2005). The isometric log-ratio transformation for waste composition was carried

183 out by means of R package compositions (van den Boogaart et al., 2014). We also used other R

184 packages for linear mixed modelling, such as faraway (Faraway and Julian, 2016), pbkrtest (Halekoh

185 and Højsgaard, 2014), lme4 (Bates et al., 2015) and RLRsim (Scheipl et al., 2008). These packages

186 have the advantage to test simultaneously fixed and random effects as well as random effect

187 individually.

\section{$188 \quad 3$ Results and discussion}

189

190

191

192

193

196

198

199

200

\subsection{Household waste generation rates}

In total, we analysed and modelled data from 303 samples, originating from 101 households over three seasons. The numbers of occupants in these houses are shown in Table 2. On average, the number of occupants per household was 2.4 people, which corresponds to the average Danish household size (Statistics Denmark, 2017).

The average waste generation rates amounted to $9.6 \pm 4.5 \mathrm{~kg}$ per household per week (or $4.0 \pm 2.4 \mathrm{~kg}$ per person) in the autumn, $9.9 \pm 5.1 \mathrm{~kg}$ per household (or $4.0 \pm 2.3 \mathrm{~kg}$ per person) in the summer and $9.2 \pm 5.2 \mathrm{~kg}$ per household $(3.8 \pm 2.5 \mathrm{~kg}$ per person) in the winter (Table 3$)$. As a result, the highest waste generation rate was observed in the summer, whereas the lowest was in the winter. The difference between estimates (means and median) is substantial and is linked to the violation of normal distribution assumption and the presence of "outlying" values (see SM Figures 1-3). The arithmetic means were higher than medians suggesting that the data were skewed to the right. Thus, a geometric mean may better compensate data skewness (Reimann et al., 2008). While the arithmetic mean is often used in the literature to represent a central value of a dataset, the results of this study shows that it is important to check the validity of the assumption before estimating arithmetic mean. For this reason, computing geometric mean, median, quartiles, and arithmetic mean provides a 
complete information about household waste generation patterns (Edjabou et al., 2017).

Overall, the highest coefficient of variation (CV) was observed in the winter (57 and $66 \%$ per household and per week, respectively) and the lowest in the autumn (47 and 53\%). The coefficient of variation of waste generation rate ranged from 48 to $57 \%$ for waste generation per household and from 53 to $66 \%$ for waste generation per person (Table 3). Thus, the dataset of waste per household was less "dispersed" than the mass estimated per person, indicating that mass per household may be preferred over mass per person as a best measure of the waste generation rate, thus confirming previous suggestions by Reimann et al. (2008). However, for this study, we analysed both datasets.

\section{Table 3}

The results of the mixed linear model applied to the generation rates do not indicate a significant difference in average waste both per household $(\mathrm{df}=2, \mathrm{~F}$-value $=1.23$, $\mathrm{p}$-value $=0.39)$ and per person $(\mathrm{df}=2, \mathrm{~F}$-value $=0.64, \mathrm{p}$-value $=0.75)$ between seasons (Table 4). A plausible explanation for this is that fresh food, including imported out-of-season products, is available throughout the whole year in the Danish food supply chain (Edjabou et al., 2016). Additionally, the significant packaging used to preserve and keep food fresh for longer periods during transportation and storage ends up in residual household in all seasons (Edjabou et al., 2015a; Lockrey, 2013).

The results also show there was a significant difference between household sizes in the waste generation per household $(\mathrm{df}=3$, mass per household $(\mathrm{F}$-value $=22.68$, $\mathrm{p}$-value $<0.001)$ and per person $(\mathrm{F}$-value $=6.42, \mathrm{p}$-value $<0.001)$ (see Table 4). Furthermore, the average waste generation rate per household increased significantly in line with the number of occupants, regardless of the season, as shown in Figure 1.I. In contrast, waste generation per person decreased significantly according to the number of occupants in the house (Figure 1.II). Remarkably, similar waste generation patterns were observed in all the seasons, confirming that there was no significant difference in the mass of 
household waste between seasons. While these results corroborate the findings of both WRAP (2009) and Edjabou et al. (2016), who suggested that the mass of household waste is affected significantly 231 by household size, they do differ from previously published studies (e.g. Boer et al.2010; Denafas et al., 2014 and Gómez et al., 2009).

\section{Table 4.}

The statistical analysis revealed no significant interaction between seasonal variations and household size in the generation of residual waste $(\mathrm{df}=6, \mathrm{~F}$-value $=1.00, \mathrm{p}$-value $=0.43$ for $\mathrm{kg} /$ household $/$ week and $\mathrm{df}=6, \mathrm{~F}$-value $=0.50, \mathrm{p}$-value $=0.81$ for $\mathrm{kg} / \mathrm{person} /$ week $)$, as shown in Table 5 and in Figure 1. $\left(\chi^{2}(1)=39.48, p\right.$-value $<0.001$ ) (Table 5). Results for waste generation rate per household are

244 illustrated in Figure 2 (see SM Figure 4for waste generation per person). Here, horizontal lines represent the mean and its $95 \%$ confidence interval of mass of waste in each of the 101 households. The $95 \%$ confidence intervals excluding zero (vertical line x-axis) correspond to a statistically significant difference between the average waste generation rate in individual house (for the three seasons) and the overall average and vice versa. We deduced that the average generation rate of residual waste in $10 \%$ of houses was significantly higher than the overall average. In contrast, 250 average residual waste was significantly lower in $5 \%$ of households compared to the overall average. 251 This discrepancy in waste generation within houses may be due to inherent or lifestyle activities in 252 individual households, and it may not necessarily be associated with seasonal variations. These 253 findings may have important implications for planning waste collection systems (collection 254 frequency and volume of waste bin). Whilst there is usually a standard volume of waste bins for all 
255 households, our results suggest that households should be offered the possibility to request an extra

$256 \mathrm{bag}$, in case the volume of their waste exceeds the capacity of their waste bin. This solution is possibly 257 more cost-effective than changing the volume of the waste bin (Nilsson, 2010). Owing to these 258 results, models predicting the mass of household waste should consider random effects, in order to 259 avoid biased estimations.

260

\section{Table 5}

\section{Figure 2:}

\subsection{Composition of residual household waste}

A comparative summary of the composition (percentage wet mass) of residual household waste for the three seasons is presented in Table 6. The descriptive statistics for individual fractions consist of (1) a classical statistics summary, including skewness (measures a distribution's departure from symmetry about its mean), kurtosis (measures the shape of the data), median, arithmetic mean (MEAN), back transformed of log mean (MEAN-log), standard deviation (SD) and coefficient of variation $(\mathrm{CV})$; (2) A compositional data analysis (CoDa) summary involving the geometric mean (Center), the robust geometric mean (Center-R) and the percentage distribution of total variance (clrvariation in\%), as suggested by Edjabou et al. (2017). Here, the robust geometric mean deals effectively with the problem of outliers and heavy-tailed distributions (Templ et al., 2016).

Regardless of statistical methods, a clear general pattern is noticeable. First, food waste (40$54 \%$ ) represents the largest proportion of residual household waste in all three seasons, followed by paper and combustible waste fractions. Second, inert gardening waste and metal have the lowest percentages in all three seasons. Third, the highest percentage of food waste was observed in autumn (45-54\%) followed by summer (43-50\%).

Overall, misplaced waste fractions (gardening waste, paper, board, metal and plastic package) amounted to $18-30 \%$ of residual household waste.

Page 13 of 22 
For the three seasons, geometric mean estimates (47-55\%) were higher than the arithmetic mean $282(40-45 \%)$ for food waste, while the opposite was found for inert waste (Table 6). This apparent discrepancy is explained by a violation of normal distribution when computing the arithmetic mean.

284 First, the results presented in Table 6 indicate that the compositions of all the waste fractions exhibit 285 a skewed distribution (skewness higher than \pm 2 ), possibly violating the normality assumption 286 (Wilcox, 2012). Second, there is large difference between arithmetic mean and median estimates, 287 signifying that the former might be influenced by extreme values. In contrast, the isometric log-ratio 288 transformation of the waste composition dataset approximates symmetric distribution. Thus, a 289 geometric mean based on the log-ratio addresses the normality assumption and seems more reliable than the arithmetic mean.

\section{Table 6.}

292

Most waste fractions have a high coefficient of variation (above 50\%), the highest of which were found for garden waste in winter (269\%) and inert in summer (162\%). Additionally, these fractions have the highest coefficients of variation in the three seasons. Overall, the coefficients of variation of individual fractions differ among seasons and are hence hardly comparable. The results of the percentage composition of food waste are consistent with the results discussed in Edjabou et al. (2016).

The total variance and its relative distribution (\% clr-var) quantify and compare the variability of the percentage for individual waste fractions. The results from the total variance distribution show that inert and gardening waste fractions contributed greatly (i.e. $~ 70 \%$ ) to total variability in residual waste over the three seasons. On the contrary, the proportions of other waste fractions varied only

303 slightly among households, due to the low contribution made to the total variation (less than $10 \%$ ).

304 Overall, the contribution of individual waste fractions to the total variance changed slightly over the 305 three seasons. Similar conclusions were reached when comparing residual waste composition 
between seasons, using the geometric mean bar plots in Figures 3 and 4. The results indicate that large differences between seasons appear primarily in garden waste. Based on Eq.(2), $\boldsymbol{X}_{\boldsymbol{m}}$ values for gardening waste were $-0.83,-0.56$ and 1.39 for autumn, winter and summer, respectively (see Figure3). Given Eq. (3), $k_{m}$ values for gardening were $0.43,0.57$ and 4.03 for autumn, winter and summer, respectively. The interpretation is that $57 \%\left(\mathrm{r}_{\mathrm{m}}=k_{m}-1=0.43-1\right)$ and $43 \%$ less gardening waste was generated in autumn and winter compared to average gardening waste. On the other hand, the generation of garden waste in summer was $303 \%\left(\mathrm{r}_{\mathrm{m}}=k_{m}-1=4.03-1\right)$ of the average (see SM Tables 2-4). Whilst these results are not surprising, they are in good agreement with those of Boldrin and Christensen (2010), who found that garden waste levels vary substantially during the year, with sizeably large quantities in summer. As mentioned in Boldrin and Christensen (2010), the reason is merely climatic: increased biomass is generated in gardens in summertime because of more insulation, longer days and higher temperatures, which in turn represent more pleasant conditions for gardening activities during which garden waste is collected. Small bars are observed for other misplaced waste fractions (paper, board, plastic packaging and metal), plastic films and combustible waste fractions, indicating that the average proportions of these fractions change slightly throughout the three seasons (Figure 3).

\section{Figure 3}

The geometric mean bar plot for residual household waste as a function of household size is shown in Figure 4. Households with one occupant had lower proportions of food waste (-43\%), gardening waste $(-72 \%)$, plastic $(-45 \%)$, metal $(-36 \%)$ and inert $(-72 \%)$ waste fractions than the average (see Figure 4 and SM Tables 6-9); nonetheless, the proportion of paper was $25 \%$ higher than the average. Households occupied by three persons had higher proportions of food waste (18\%), gardening waste $(155 \%)$, paper (19\%), metal (39\%) and inert (199\%) waste fractions than the 
average. Overall, misplaced waste fractions (gardening waste, paper, board, metal and plastic package) amounted to $18-33 \%$ of residual household waste.

\section{Figure 4}

The results of the multivariate linear mixed model applied to isometric log-ratio coordinates showed no significant difference in the composition of residual waste between seasons $(\mathrm{df}=2$, Fvalue $=0.25, \mathrm{p}$-value $=0.78)$ or within households $\mathrm{df}=3, \mathrm{~F}$-value $=2.04, \mathrm{p}$-value $=0.11)$ (see Table 4) despite the differences shown in Figures 3 and 4. It should be noted that Table 4 (dataset of waste composition) presents results based on the isometric log-ratio coordinates.

For individual waste fractions, a pairwise comparison between seasons based on bootstrap percentile confidence intervals $(B=1000)$ is presented in Figure 5. For example, differences in the proportion of gardening waste were $-1.89 \%$ (with $95 \%$ CI from -4.52 to 0.96 ) between summer and winter, $0.38 \%$ (with $95 \%$ CI from -2.73 to 3.34 ) between autumn and winter and $-2.26 \%$ (with $95 \%$

CI from -4.88 to 0.51 ) between autumn and summer. Moreover, for the difference in proportions for food waste, we found $-0.05 \%$ (with $95 \%$ CI from -0.41 to 0.28 ) between summer and winter, $-0.12 \%$ (with $95 \%$ CI from -0.45 to 0.10 ) between autumn and winter and $0.08 \%$ (with $95 \%$ CI from -1.16 to 0.0 .34 ) between autumn and summer. These confidence intervals include zero, suggesting no significant difference in the proportion of garden waste and food waste between seasons, as shown in Figure 5. Overall, large differences were observed for gardening, inert and metal waste for all seasons (longer dashed lines). However, the percentile intervals of all the waste fractions included a zero value (no significance differences). This is illustrated in Figure 5, where all the dashed lines crossed the x-axis (see SM Tables 10).

These findings are contrary to most previous studies, which have suggested that seasonal variations may influence significantly household waste composition (e.g. Boer et al., 2010; Denafas 
354 et al., 2014; Edjabou et al., 2012; Gómez et al., 2009). Several factors may explain these 355 discrepancies. As an example, Boer et al. (2010) found that in Poland, households using a local gas 356 and coal (coke) system generated significantly higher amounts of waste in winter, the composition 357 of which varied significantly throughout the seasons. Moreover, Edjabou et al. (2012) and Gómez et 358 al. (2009) reported significantly higher food waste generation during the rainy season and summer, 359 respectively, in Togo and in Mexico. However, these locations have remarkably different socio360 geographic characteristics compared to those in Denmark, making a direct comparison meaningless.

361 Generally, in cases where decentralised heating systems based on coal or biomass are used, ash 362 generation increases considerably, thereby markedly affecting household waste generation and 363 composition during winter. Additionally, most Danish households purchase their food and fresh 364 vegetable on a short-time basis regardless of the season (Edjabou et al., 2016). Another reason is that 365 garden waste (grass clippings, hedge cuttings and soil) generated during summer is disposed of in 366 waste recycling centres (Boldrin and Christensen, 2010). Only indoor flowers that represent a 367 relatively small amount (less than $1 \%$ of the residual household waste) are misplaced, usually in 368 residual waste. Moreover, seasonal variations and household sizes did not significantly influence the 369 percentage of other misplaced recyclable materials (i.e. paper, board, plastic and metal) in household 370 waste.

371

372 373

374

375

376

377

378

\section{Figure 5}

\subsection{Limitations and application of these results}

The present findings suggest that when waste composition is analysed, sampling should first be performed from all household sizes in the study area. Then, to obtain an average composition, the data should be aggregated (i.e. weighted) according to the distribution of household size in the population (European Commission, 2004). We can conclude that a waste composition dataset 
representative of the whole year can be obtained from waste sampled for at least a full week from a representative group of households covering the different socio-economic and geographical conditions of the area. Participation in source-segregating recyclables (i.e. paper, board and plastic packaging and metal) may not be influenced significantly by seasonal variations.

For this study, residual household waste was sorted into nine waste fractions. Analysis of a more detailed waste fraction may not necessarily generate similar results. Additionally, owing to countryspecific socio-economic conditions, these data could be applied to countries with important similarities to Denmark.

During the recent years, various software (e.g. CoDaPack, R) and packages (Oksanen, 2015; Templ et al., 2016; van den Boogaart, 2008) for the statistical analysis of compositional data have been developed and freely available. The advantage of these software and packages is that they do not require extensive programming skills. Therefore, we urge practitioners to use compositional data analysis technique to analyse waste composition data.

\section{Conclusions and perspectives}

To investigate the influence of seasonal variations and household size on the generation rates and composition of residual household waste, the sampling and characterisation of waste were performed for 101 Danish households in summer, autumn and winter. The results of the statistical analysis showed that the generation and composition of residual household waste is not significantly affected by seasonal variations. Therefore, for this study area, seasonal variations do not contribute to the periodic heterogeneity fluctuation error. Conversely, household size does influence significantly the generation rate (mass) of residual household waste, but not the waste composition. Consequently, household size is a critical parameter in sampling residual household waste, in order to estimate the mass of waste generated in a house. Accordingly, it is recommended 
that the estimated generation rates of residual household waste are aggregated and based on household size, to avoid fluctuation errors that may be introduced by household size distribution.

\section{Acknowledgments}

The authors acknowledge the Danish Environmental Protection Agency (EPA), the municipalities of Gladsaxe and Claus Petersen from ECONET AS for giving us their permission to use these data and for their valuable contributions. Our gratitude goes also to Josep Antoni Martín-Fernández from the Department of Computer Science, Applied Mathematics and Statistics, University of Girona, Campus Montilivi (P4) for his valuable contribution to the statistical analyses employed in this study.

\section{Appendix A. Supplementary data}

\section{References}

Aguilar-Virgen, Q., Taboada-González, P., Ojeda-Benítez, S., 2013. Seasonal analysis of the generation and composition of solid waste: potential use--a case study. Environmental monitoring and assessment 185, 4633-45. doi:10.1007/s10661-012-2893-5

Aitchison, J., 1994. A Concise Guide to Compositional Data Analysis. Lecture Notes-Monograph Series 24, 73-81.

Aitchison, J., 1986. The Statistical Analysis of Compositional Data. Monographs on Statistics and Applied Probability. Chapman \& Hall Ltd., London (UK). Reprinted (2003) with additional material by The Blackburn Press, Caldwell, NJ.

Aitchison, J., Ng, K.W., 2005. The role of perturbation in compositional data analysis. Statistical Modelling 5, 173-185. doi:10.1191/1471082X05st091oa

Andersen, F.M., Larsen, H. V., 2012. FRIDA: A model for the generation and handling of solid waste in Denmark. Resources, Conservation and Recycling 65, 47-56. doi:10.1016/j.resconrec.2012.04.004

Bates, D., Maechler, M., Bolker, B., Walker, S., 2015. Fitting Linear Mixed-Effects Models Using lme4. Journal of Statistical Software 67, 1-48. doi:10.18637/jss.v067.i01 
Berridge, D., Crouchley, R., 2011. Multivariate Generalized Linear Mixed Models Using R 304.

Boer, E. Den, Jedrczak, A., Kowalski, Z., Kulczycka, J., Szpadt, R., 2010. A review of municipal solid waste composition and quantities in Poland. Waste management (New York, N.Y.) 30, 369-77. doi:10.1016/j.wasman.2009.09.018

Boldrin, A., Christensen, T.H., 2010. Seasonal generation and composition of garden waste in Aarhus (Denmark). Waste Management 30, 551-557. doi:10.1016/j.wasman.2009.11.031

Dahlén, L., Lagerkvist, A., 2008. Methods for household waste composition studies. Waste management (New York, N.Y.) 28, 1100-12. doi:10.1016/j.wasman.2007.08.014

Denafas, G., Ruzgas, T., Martuzevičius, D., Shmarin, S., Hoffmann, M., Mykhaylenko, V., Ogorodnik, S., Romanov, M., Neguliaeva, E., Chusov, A., Turkadze, T., Bochoidze, I., Ludwig, C., 2014. Seasonal variation of municipal solid waste generation and composition in four East European cities. Resources, Conservation and Recycling 89, 22-30. doi:10.1016/j.resconrec.2014.06.001

Edjabou, M.E., Boldrin, A., Scheutz, C., Astrup, T.F., 2015a. Source segregation of food waste in office areas: Factors affecting waste generation rates and quality. Waste Management 46, 94 102. doi:10.1016/j.wasman.2015.07.013

Edjabou, M.E., Jensen, M.B., Götze, R., Pivnenko, K., Petersen, C., Scheutz, C., Astrup, T.F., 2015b. Municipal solid waste composition: Sampling methodology, statistical analyses, and case study evaluation. Waste Management 36, 12-23. doi:10.1016/j.wasman.2014.11.009

Edjabou, M.E., Møller, J., Christensen, T.H., 2012. Solid waste characterization in Ketao, a rural town in Togo, West Africa. Waste management \& research: the journal of the International Solid Wastes and Public Cleansing Association, ISWA 30, 745-9. doi:10.1177/0734242X12442741

Edjabou, M.E., Petersen, C., Scheutz, C., Astrup, T.F., 2016. Food waste generation and composition in Danish households. Waste Management 52, 256-268. doi:10.1007/s13398014-0173-7.2

Edjabou, M.E., Pivnenko, K., Petersen, C., Scheutz, C., Astrup, T.F., 2015c. Compositional data analysis of household food waste in Denmark. Abstract from 6th International Workshop on Compositional Data Analysis.

Edjabou, M.E., Scheutz, C., Astrup, T.F., 2017. Statistical analysis of solid waste composition data: Arithmetic mean, standard deviation and correlation coefficients. Waste Management 69, 1323. doi:10.1016/j.wasman.2017.08.036.

Egozcue, J.J., Pawlowsky Glahn, V., Mateu-Figueras, G., Barceló Vidal, C., 2003. Isometric logratio for compositional data analysis. Mathematical geology 35, 279-300. doi:10.1023/A:1023818214614

European Commission, 2004. Methodology for the Analysis of Solid Waste (SWA-tool). User Version 43, 1-57.

Faraway, 2016. Extending the linear model with R: generalized linear, mixed effects of nonparametric regression models. Chapman \& Hall.

Faraway, Julian, 2016. faraway: Functions and Datasets for Books by Julian Faraway.

Gómez, G., Meneses, M., Ballinas, L., Castells, F., 2009. Seasonal characterization of municipal 
solid waste (MSW) in the city of Chihuahua, Mexico. Waste management (New York, N.Y.) 29, 2018-24. doi:10.1016/j.wasman.2009.02.006

Halekoh, U., Højsgaard, S., 2014. A Kenward-Roger Approximation and Parametric Bootstrap Methods for Tests in Linear Mixed Models - The R Package pbkrtest. Journal of Statistical Software 59, 1-30.

Kamran, A., Chaudhry, M.N., Batool, S.A., 2015. Effects of socio-economic status and seasonal variation on municipal solid waste composition: a baseline study for future planning and development. Environmental Sciences Europe 27, 16. doi:10.1186/s12302-015-0050-9

Kynčlová, P., Filzmoser, P., Hron, K., 2015. Modeling compositional time series with vector autoregressive models. Journal of Forecasting 34, 303-314. doi:10.1002/for.2336

Lockrey, S., 2013. FINAL REPORT: The role of packaging in minimising food waste in the supply chain of the future $0-49$.

Nilsson, P., 2010. Waste Collection: Equipment and Vehicles, in: Christensen, T.H. (Ed.), Solid Waste Technology \& Management, Volume 1 \& 2. John Wiley \& Sons, Ltd, Chichester, UK.

Nordtest, 1995. Municipal solid waste: Sampling and characterisation (No. NT ENVIR 001), Nordtest Method. Espoo, Finland.

Pawlowsky-glahn, V., Egozcue, J.J., Lovell, D., 2015. Tools for compositional data with a total 15, 175-190.

Pitard, F.F., 1993. Pierre Gy's Sampling Theory and Sampling Practice, Second Edition: Heterogeneity, Sampling Correctness, and Statistical Process Control. CRC Press.

R Core Team, 2017. R: A Language and Environment for Statistical Computing.

Reimann, C., Filzmoser, P., Garrett, R.G., Dutter, R., 2008. Statistical Data Analysis Explained: Applied Environmental Statistics With R, Statistical Data Analysis Explained: Applied Environmental Statistics With R. John Wiley \& Sons, Ltd, Chichester, UK. doi:10.1002/9780470987605

Riber, C., Petersen, C., Christensen, T.H., 2009. Chemical composition of material fractions in Danish household waste. Waste management (New York, N.Y.) 29, 1251-7. doi:10.1016/j.wasman.2008.09.013

Scheipl, F., Greven, S., Kuechenhoff, H., 2008. Size and power of tests for a zero random effect variance or polynomial regression in additive and linear mixed models. Computational Statistics \& Data Analysis 52, 3283-3299.

Schutz, R.W., Gessaroli, M.E., 1987. The analysis of repeated measures designs involving multiple dependent variables. Research Quarterly for Exercise and Sport 58, 132-149.

Statistics Denmark, 2017. BOL103: Dwellings by county, type of resident, type of dwelling, number of rooms, size of dwelling in square metre and household size [WWW Document]. URL http://www.statistikbanken.dk/BOL103

Templ, A.M., Hron, K., Filzmoser, P., Templ, M.M., 2016. robCompositions: R-package for robust statistical analysis of compositional data. Compositional Data Analysis. Theory and Applications 241-355.

Thió-Henestrosa, S., Martín-Fernández, J.A., 2005. Dealing with compositional data: The freeware 
US EPA, O. of R.C. and R., 2002. RCRA Waste Sampling Draft Technical Guidance Planning, Implementation, and Assessment (No. EPA530-D-02-002), Solid Waste and Emergency Response (5305W).

514 van den Boogaart, K.G., Tolosana, R., Bren, M., 2014. compositions: Compositional Data Analysis.

Wilcox, R., 2012. Introduction to Robust Estimation and Hypothesis Testing, Introduction to Robust Estimation and Hypothesis Testing. Elsevier. doi:10.1016/B978-0-12-386983-8.00008-

518 WRAP, 2009. Household Food and Drink Waste in the UK, October. Banbury, UK. doi:10.1111/j.1467-3010.2011.01924.x 
3 Compositional analysis of seasonal variation in Danish residual household waste

5 Maklawe Essonanawe Edjabou*, Alessio Boldrin, and Thomas Fruergaard Astrup

7 Department of Environmental Engineering, Technical

8 University of Denmark, 2800 Kgs. Lyngby, Denmark

9

10

11

12

13

14

15

16

17

*) Corresponding author: vine@env.dtu.dk;

Phone number: +4545251498

18

19

20

Page 1 of 7 
21 Table 1: List of residual household waste fractions and components included (based on Edjabou et al., 2015)

\begin{tabular}{ll}
\hline Waste fractions & Components \\
\hline Food waste (Food) & $\begin{array}{l}\text { Vegetable and animal derived food waste: } \\
\text { Fresh fruit, fresh carrots and potatoes, bread, cereals, residues from fruits, vegetables, } \\
\text { coffee grounds, rest of food containing meat }\end{array}$ \\
\hline Gardening waste (Garden) & Flowers, \\
\hline Paper & $\begin{array}{l}\text { Advertisements, books \& booklets, magazines \& Journals, newspapers } \\
\text { office paper, phonebooks, miscellaneous paper }\end{array}$ \\
\hline Board & Corrugated boxes, beverage cartons, folding boxes, miscellaneous board \\
\hline Plastic packaging (Plastic) & Packaging plastics, PET/PETE (1), HDPE (2), PVC/V (3), LDPE/LLDPE (4), PP (5) \\
\hline Plastic film (Plastic foil) & $\begin{array}{l}\text { PS (6) non-foamed, PS (6) foamed, Other plastic resins labelled with [1-19] (7), } \\
7 \text { ) or ABS, Unidentified plastic resin }\end{array}$ \\
\hline Metal packaging (Metal) & Pure plastic film, composite plastics \\
\hline Inert & Metal packaging containers (ferrous, non-ferrous), and composites \\
\hline Miscellaneous combustible waste & $\begin{array}{l}\text { Human hygiene waste, other combustible waste, textile, leather, rubber, vacuum cleaner } \\
\text { bags }\end{array}$ \\
\hline
\end{tabular}

Table 2: Number of households per sampling period (seasons) as a function of household size and amount of waste analysed.

\begin{tabular}{|c|c|c|c|c|c|c|c|}
\hline \multirow{2}{*}{ Year } & \multirow{2}{*}{ Seasons } & \multicolumn{4}{|c|}{ Number of households as function of household size ${ }^{a}$} & \multirow{2}{*}{$\begin{array}{l}\text { Total number of } \\
\text { households }^{\mathrm{b}}\end{array}$} & \multirow{2}{*}{$\begin{array}{l}\text { Total residual waste } \\
\text { kg wet mass }^{\mathrm{c}}\end{array}$} \\
\hline & & $1 \mathrm{p}$ & $2 p$ & $3 p$ & $4 p$ & & \\
\hline 2011 & Summer & 15 & 45 & 13 & 28 & 101 & 1005 \\
\hline 2011 & Autumn & 15 & 45 & 13 & 28 & 101 & 974 \\
\hline 2012 & Winter & 15 & 45 & 13 & 28 & 101 & 932 \\
\hline
\end{tabular}

${ }^{a}$ Households containing one (1p), two (2p), tree (3p) and more than three $(+4 p)$ persons,

Table 3: Descriptive statistics of residual household waste generation rates as a function of seasonal variations (wet mass): $\mathrm{N}=101$ households per season. Values are rounded to two decimal places.

\begin{tabular}{|c|c|c|c|c|c|c|}
\hline \multirow{2}{*}{ Parameters } & \multicolumn{3}{|c|}{ Mass per household per week } & \multicolumn{3}{|c|}{ Mass per person per week } \\
\hline & Summer & Autumn & Winter & Summer & Autumn & Winter \\
\hline MEDIAN (kg) & 9.14 & 10.28 & 8.58 & 3.77 & 3.42 & 3.14 \\
\hline $\mathrm{MAD}^{\mathrm{a}}(\mathrm{kg})$ & 5.77 & 5.44 & 6.10 & 1.33 & 1.58 & 1.83 \\
\hline MEAN- $\log ^{\mathrm{b}}(\mathrm{kg})$ & 8.34 & 8.24 & 7.47 & 3.52 & 3.48 & 3.15 \\
\hline MEAN (kg) & 9.95 & 9.65 & 9.23 & 4.03 & 4.03 & 3.79 \\
\hline $\mathrm{SD}(\mathrm{kg})^{\mathrm{c}}$ & 5.07 & 4.52 & 5.25 & 2.26 & 2.12 & 2.51 \\
\hline $\mathrm{CV} \%{ }^{\mathrm{d}}$ & 50.96 & 46.88 & 56.88 & 56.04 & 52.55 & 66.04 \\
\hline $\mathrm{Q} 1^{\mathrm{e}}$ & 6.06 & 5.91 & 4.99 & 2.75 & 2.67 & 2.18 \\
\hline $\mathrm{Q}^{\mathrm{f}}$ & 13.86 & 13.06 & 13.58 & 4.59 & 5.21 & 4.82 \\
\hline
\end{tabular}

33 aedian absolute deviation, ${ }^{b}$ Back-transformed arithmetic mean of the log-transformed data

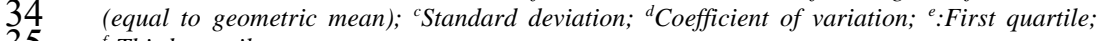

f:Third quartile. 
38 Table 4: Analysis of variance table of type III for fixed effects of waste 39 generation rates ( $\mathrm{kg} /$ household/week and $\mathrm{kg} /$ person/week) and composition

40 (percentage wet mass) using the R package 'lmerTest'

\begin{tabular}{|c|c|c|c|c|c|}
\hline & $\mathrm{DF}^{\mathrm{a}}$ & Sum $\mathrm{Sq}^{\mathrm{b}}$ & Mean $\mathrm{Sq}^{\mathrm{c}}$ & F.value & $\operatorname{Pr}(>\mathrm{F})$ \\
\hline \multicolumn{6}{|l|}{ Dataset $^{d}$ : kg/household/week } \\
\hline Seasons & 2 & 26.60 & 13.30 & 1.23 & 0.39 \\
\hline Household size & 3 & 738.80 & 246.30 & 22.68 & $<0.001 * * *$ \\
\hline Interaction (seasons and household size) & 6 & 65.00 & 10.80 & 1.00 & 0.43 \\
\hline \multicolumn{6}{|l|}{ Dataset $^{e}: \mathrm{kg} /$ person/week } \\
\hline Seasons & 2 & 3.76 & 1.88 & 0.64 & 0.75 \\
\hline Household size & 3 & 56.93 & 18.98 & 6.42 & $<0.001 * * *$ \\
\hline Interaction (seasons and household size) & 6 & 8.79 & 1.47 & 0.50 & 0.81 \\
\hline \multicolumn{6}{|c|}{ Dataset': waste composition (wet mass) transformed as isometric log-ratio } \\
\hline Seasons & 2 & 0.56 & 0.29 & 0.25 & 0.78 \\
\hline Household size & 3 & 7.16 & 2.39 & 2.04 & 0.11 \\
\hline Interaction (seasons and household size) & 6 & 5.31 & 0.89 & 0.76 & 0.60 \\
\hline
\end{tabular}

$41 \quad{ }^{a}$ Degree of freedom; ${ }^{b}$ Sum square ${ }^{c}$ mean square;

$42{ }^{d}$ Waste generation rate dataset expressed in $\mathrm{kg}$ waste per household per week

$43 \quad{ }^{e}$ Waste generation rate dataset expressed in $\mathrm{kg}$ waste per person per week

$44 \quad f$ Waste composition dataset expressed in percentage wet mass

45 Significance level: High significance probability $p<0.001^{* * *}$; () no significance-

46 probability higher than 0.05 
47 Table 5: Analysis of random effects of the linear mixed effects models for

48 waste generation rates $(\mathrm{kg} /$ household $/$ week and $\mathrm{kg} /$ person/week $)$ and

49 composition (percentage wet mass) using the R package 'ImerTest'

\begin{tabular}{|c|c|c|c|c|c|}
\hline & Variance & Std. Deva & Chi.sp ${ }^{b}$ & Chi.DF ${ }^{\mathrm{c}}$ & P.value \\
\hline \multicolumn{6}{|c|}{ Dataset $^{d}$ : kg/household/week } \\
\hline Adresse & 6.88 & 2.62 & 39.48 & 1.00 & $<0.001$ \\
\hline Residual & 10.86 & 3.30 & & & \\
\hline \multicolumn{6}{|c|}{ Dataset $^{2} \mathrm{~kg} /$ person/week } \\
\hline Adresse & 1.89 & 1.38 & 40.02 & 1.00 & $<0.001$ \\
\hline Residual & 2.96 & 1.72 & & & \\
\hline \multicolumn{6}{|c|}{ Dataset': waste composition (wet mass) transformed as isometric log-ratio } \\
\hline Adresse & 0.00 & 0.00 & 00.00 & 1.00 & 1.00 \\
\hline Residual & 1.17 & 1.08 & & & \\
\hline
\end{tabular}

$50 \quad{ }^{a}$ Standard deviation; ${ }^{b}$ Chi-square; ${ }^{c}$ Degree of freedom of chi-square

$51{ }^{d}$ Waste generation rate dataset expressed in $\mathrm{kg}$ waste per household per week

52 ' Waste generation rate dataset expressed in $\mathrm{kg}$ waste per person per week

53 Waste composition dataset expressed in percentage wet mass

54 Significance level: High significance probability $p<0.001^{* * *}$; () no significance-

55 probability higher than 0.05 
Table 6: Statistical summary of the residual waste composition (\% wet mass basis) as a function of season ( $\mathrm{N}=101$ households for each season). Values are rounded to two decimal places. CoDa is compositional data analysis.

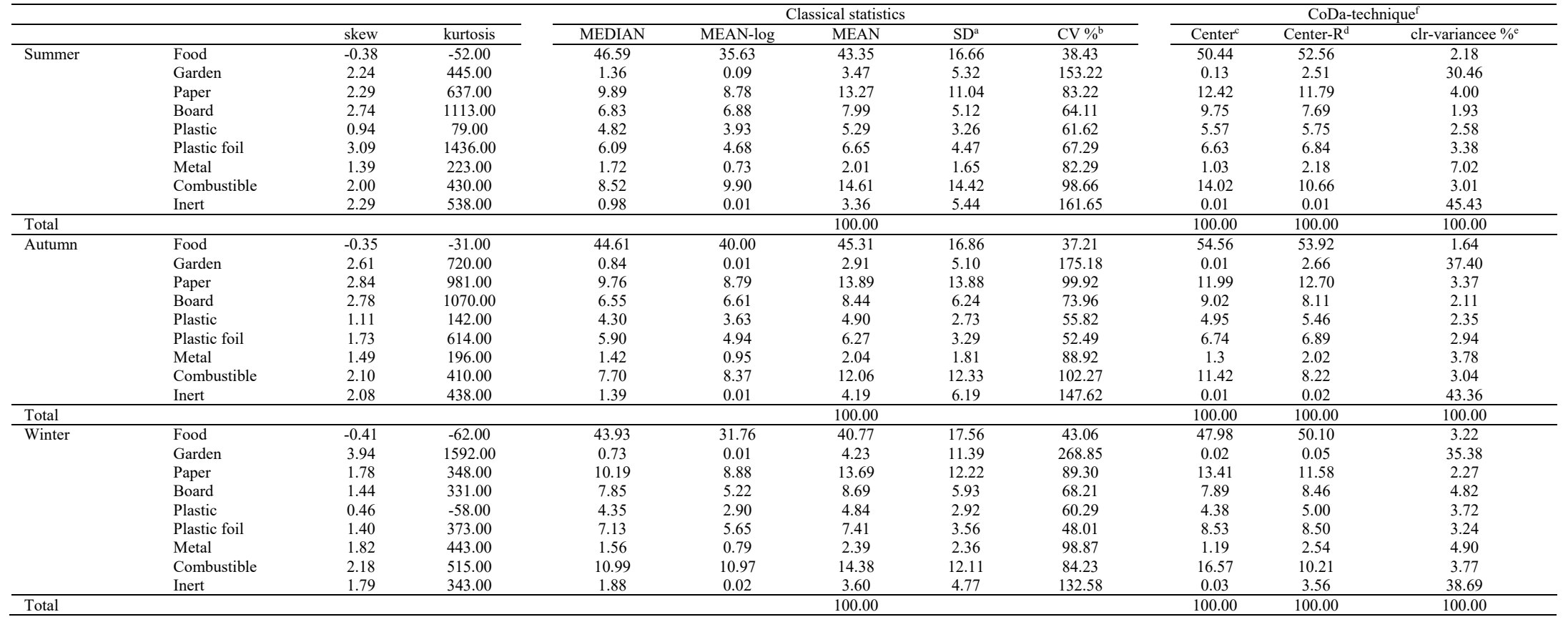

Page 5 of 7 


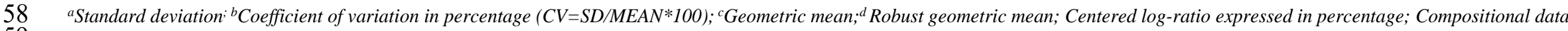
59 analysis (Edjabou et al., 2017).

Page 6 of 7 
Page 7 of 7 


\section{Figures}

Figure 1: Household size group means with 95 percent confidence intervals for the three seasons based on: (I) total residual waste generated by a household (kg /household/week), (II) total residual waste expressed per person ( $\mathrm{kg} /$ person/week). 
(I) Autumn

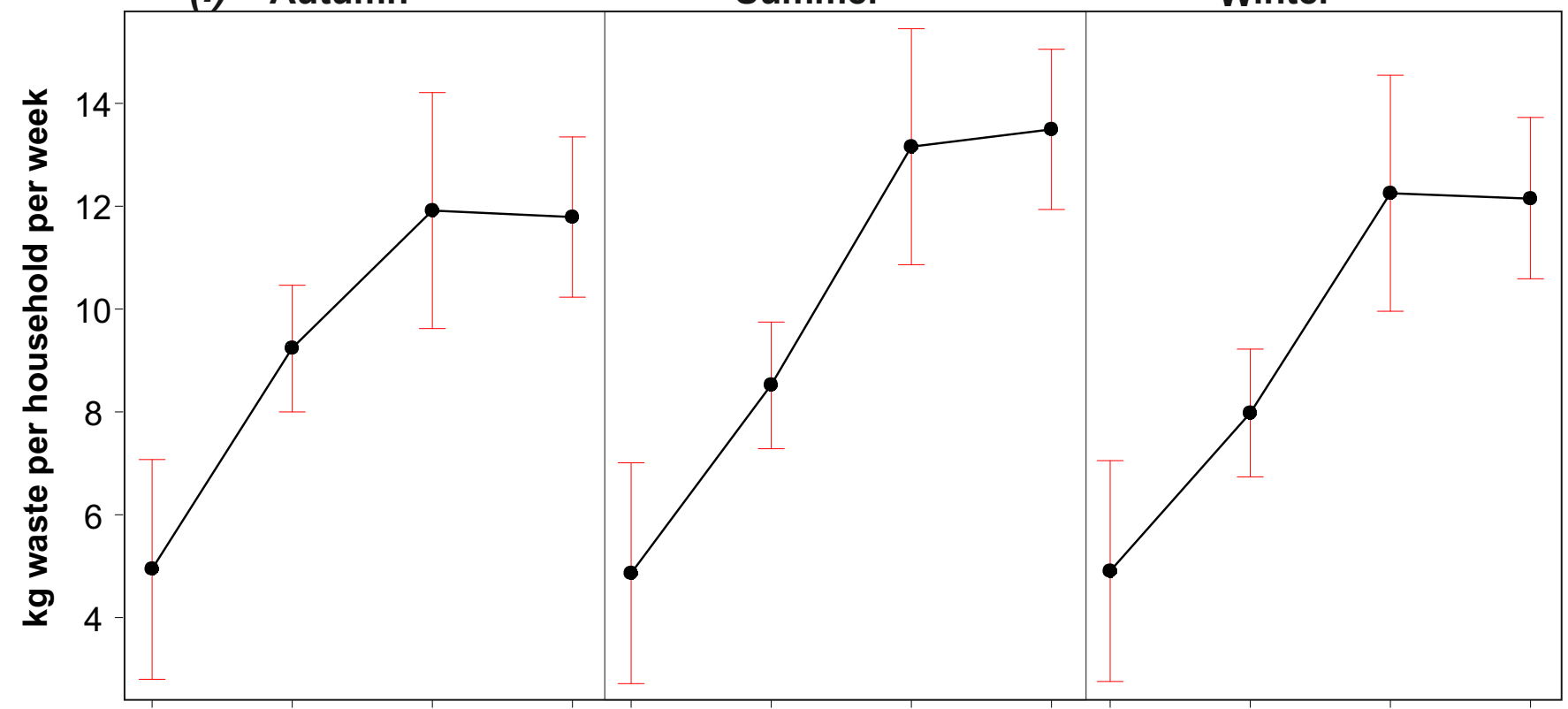

(II) Autumn

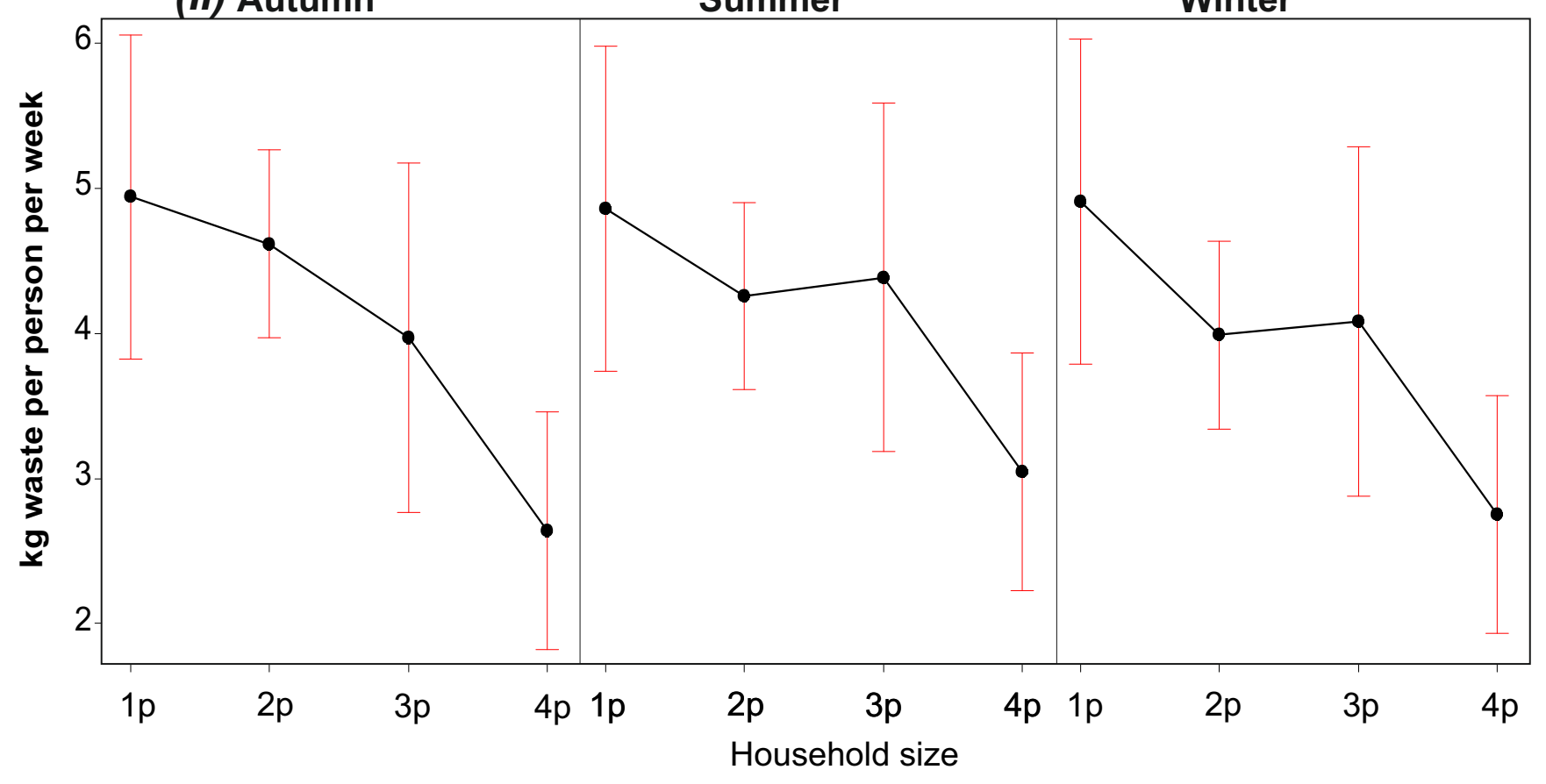


Figure 2: 95\% prediction interval on the random effects in waste generation rate per household (kg/household/week). Horizontal lines represent the mean and $95 \%$ confidence intervals of 101 households. 


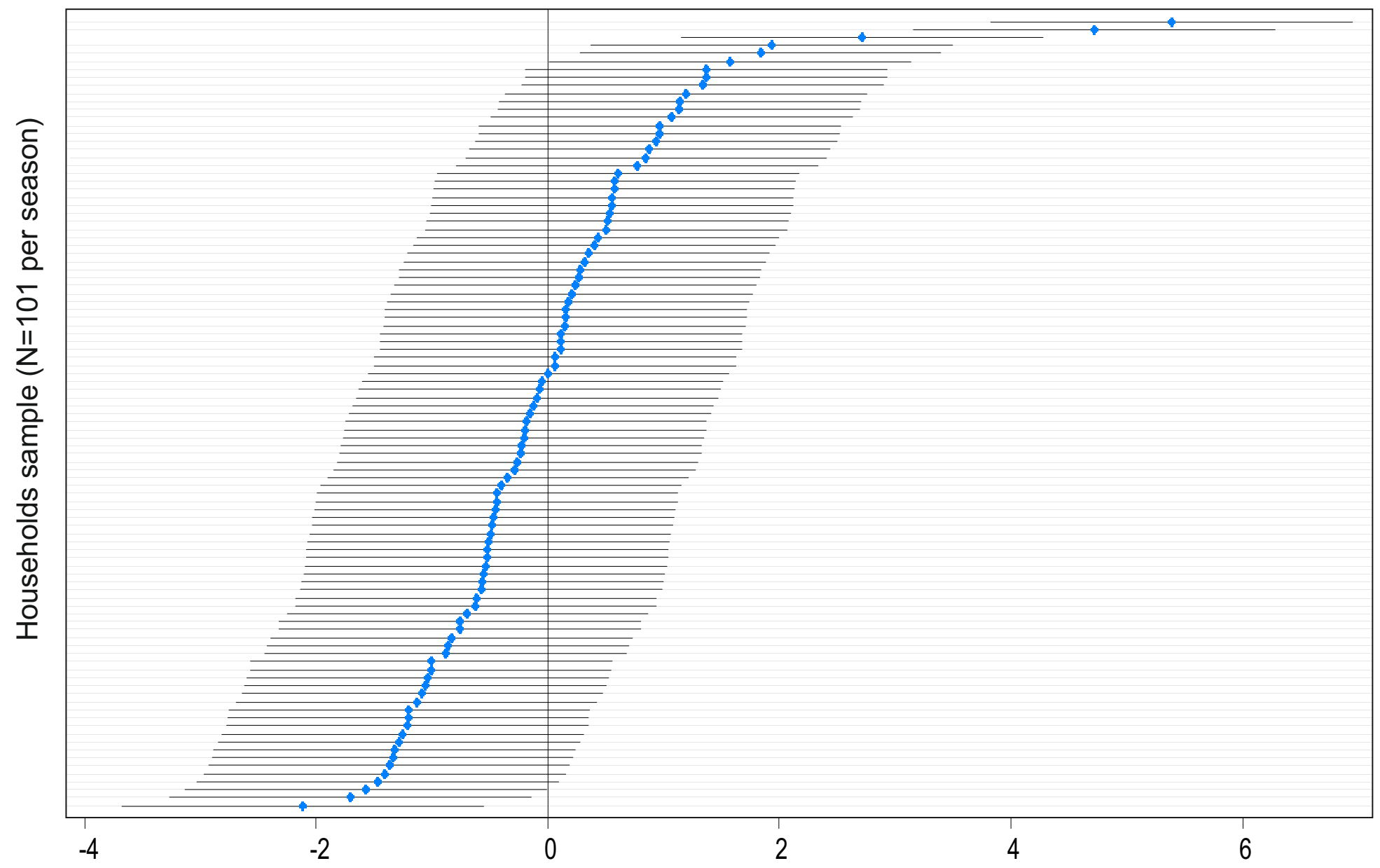

Confidence intervals for the random effects (variation through three seasons for individual household) 
Figure 3: Geometric mean barplot for residual household waste composition dataset (\% of wet mass) as function of season. The bars show the log-ratio between geometric mean of a fraction for a subgroup and the geometric mean of overall subgroups (Computation was based on Eqs. (1-3)) 


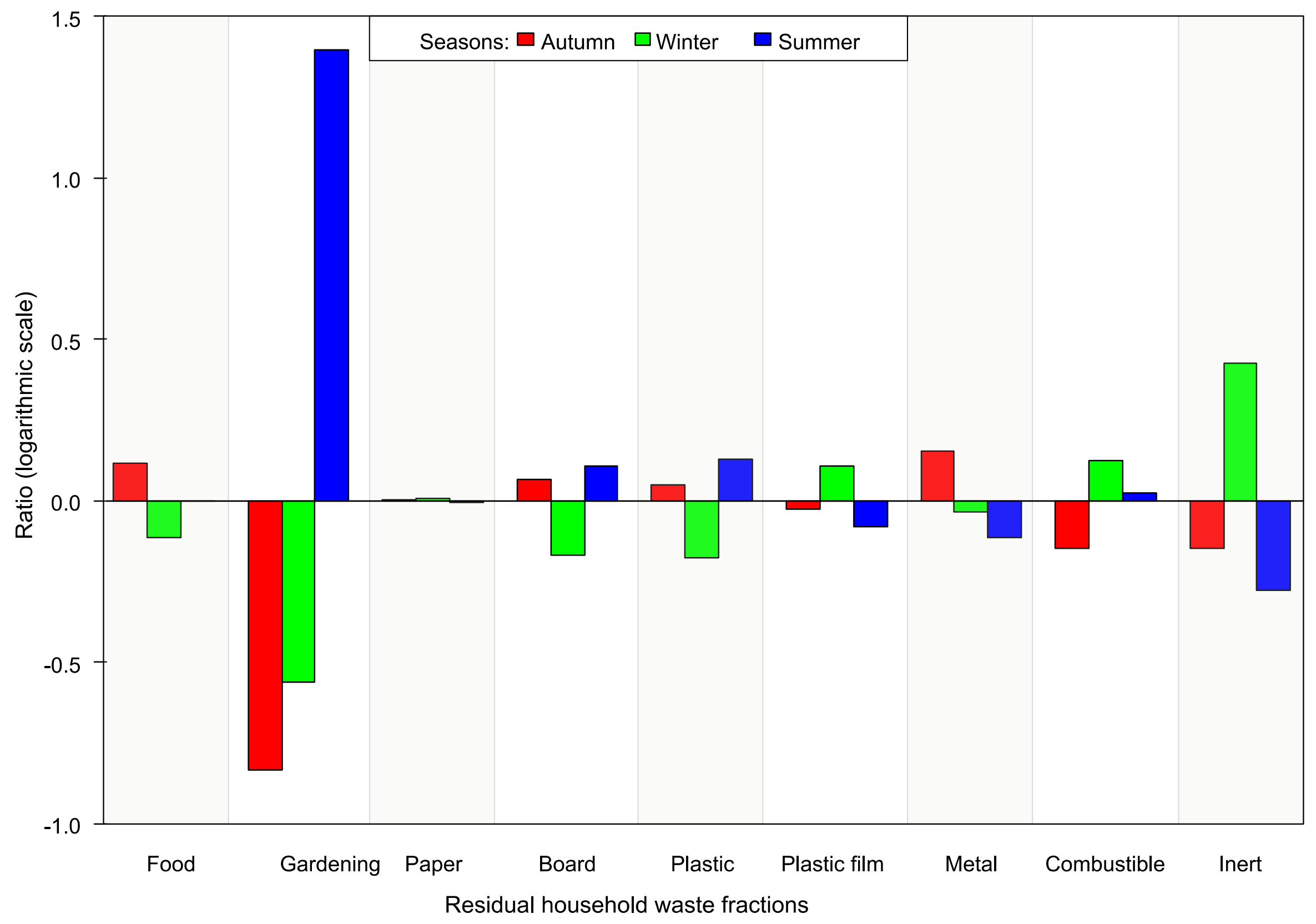


Figure 4: Geometric mean barplot for residual household waste composition dataset (\% of wet mass) as function of household size. The bars show the log-ratio between geometric mean of a fraction for a subgroup and the geometric mean of overall subgroups (Computation was based on Eqs. (1-3)) 
Figure 5: Pairwise comparison between seasons of individual waste fractions based bootstrap percentile confidence intervals $(B=1000)$ for log-ratio difference between: (A) summer and winter, (B) summer and autumn, and (C) winter and autumn. The vertical lines represent difference for the means (filled circles) and vertical dashed lines are the percentile intervals (squares show upper and lower limits). The difference is not significant when a vertical dashed line crosses $\mathrm{x}$-axis (upper and lower limits are above and under $\mathrm{x}$-axis respectively). The difference between two groups is positive and significant when the upper and lower limits are above x-axis, the opposite is true for negative and significant difference. 

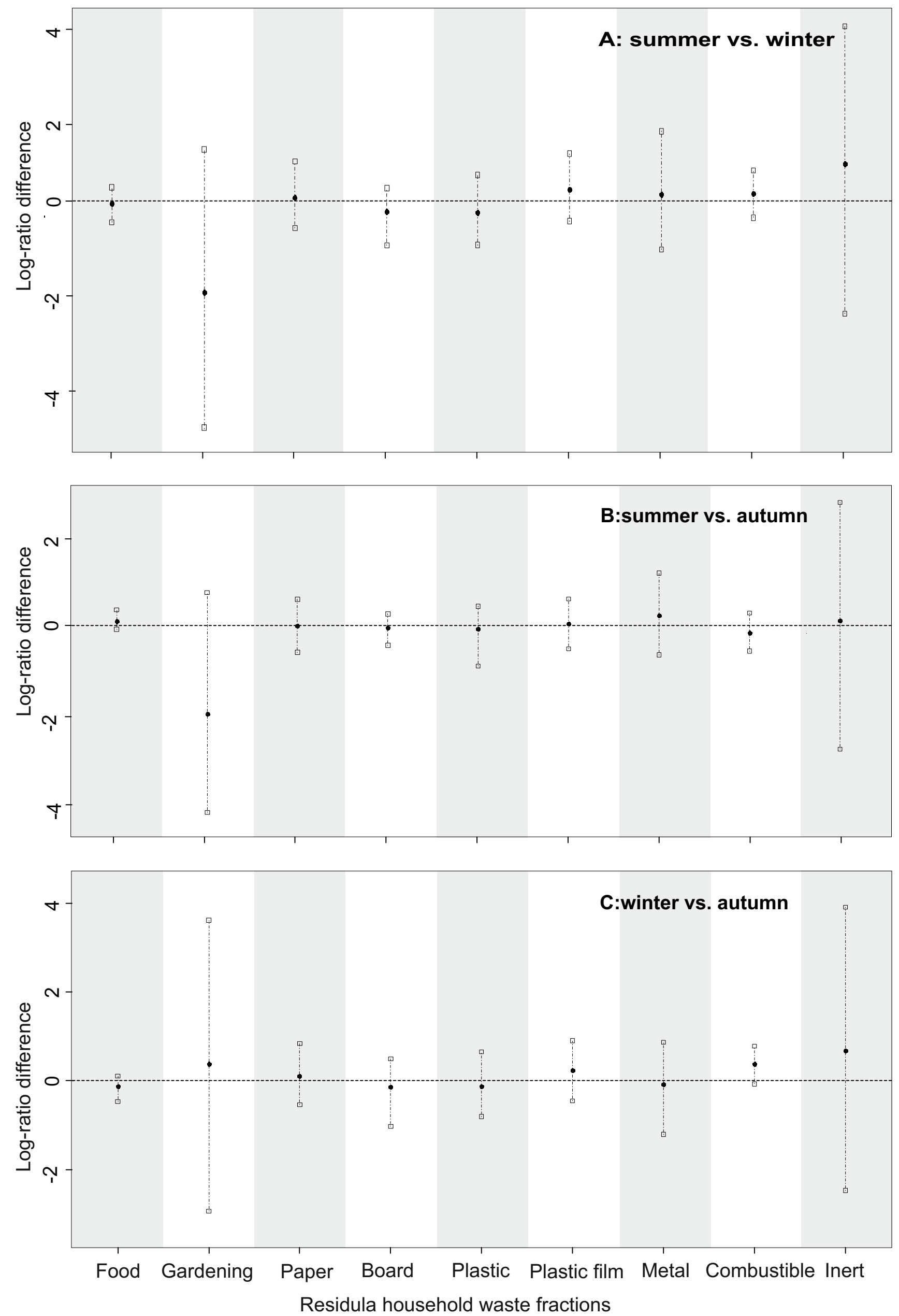


\section{Compositional analysis of seasonal variation in Danish residual household waste}

Maklawe Essonanawe Edjabou*, Alessio Boldrin, and Thomas Fruergaard Astrup

Department of Environmental Engineering, Technical University of Denmark, $2800 \mathrm{Kgs}$. Lyngby,

Denmark

*) Corresponding author: vine@env.dtu.dk;

Phone number: +4545251498 


\section{Supplementary data (SM)}

Supplementary materials contain detailed food waste data used for calculations. SMs are divided into tables (Table SM) and figures (Figure SM). 


\section{Supplementary materials (SM) - Tables}

SM Table 1: Binary partition to compute isometric log-ratio coordinates

\begin{tabular}{llllllllll}
\hline & ilr1 & ilr2 & ilr3 & ilr4 & ilr5 & ilr6 & ilr7 & ilr8 \\
\hline Food & 1 & 1 & 1 & 1 & 0 & 0 & 0 & 0 \\
Garden & 1 & 1 & 1 & -1 & 0 & 0 & 0 & 0 \\
Paper & 1 & 1 & -1 & 0 & 0 & 0 & 0 & 0 \\
Board & 1 & -1 & 0 & 0 & 1 & 0 & 0 & 0 \\
Plastic & 1 & -1 & 0 & 0 & -1 & 0 & 0 & 0 \\
Plastic foil & -1 & 0 & 0 & 0 & 0 & 1 & 1 & 0 \\
Metal & -1 & 0 & 0 & 0 & 0 & 1 & -1 & 0 \\
Combustible & -1 & 0 & 0 & 0 & 0 & -1 & 0 & 1 \\
Inert & -1 & 0 & 0 & 0 & 0 & -1 & 0 & -1 \\
\hline
\end{tabular}

SM Table 2: Geometric means of subgroups $\left(\mathrm{g}_{\mathrm{mi}}\right)$ and total average $\left(\mathrm{g}_{\mathrm{m}}\right)$. Subgroups are seasons.

These estimates were computed using Eq. 2 and correspond to the values of $\boldsymbol{X}$

\begin{tabular}{lcccccccccc}
\hline Seasons & Food & Garden & Paper & Board & Plastic & Plastic foil & Metal & Combustible & Inert \\
\hline Autumn & 40.00 & 0.01 & 8.79 & 6.61 & 3.63 & 4.94 & 0.95 & 8.37 & 0.01 \\
Winter & 31.76 & 0.01 & 8.88 & 5.22 & 2.90 & 5.65 & 0.79 & 10.97 & 0.02 \\
Summer & 35.63 & 0.09 & 8.78 & 6.88 & 3.93 & 4.68 & 0.73 & 9.90 & 0.01 \\
Total average & 35.64 & 0.02 & 8.82 & 6.20 & 3.46 & 5.07 & 0.82 & 9.69 & 0.01 \\
\hline
\end{tabular}

SM Table 3: Results of log of the ration between geometric mean of subgroups and the average geometric mean. Subgroups are seasons. These estimates were computed using Eq. 2 and correspond to the values of $\boldsymbol{X}$

\begin{tabular}{lcccccccccc}
\hline Seasons & Food & Garden & Paper & Board & Plastic & Plastic foil & Metal & Combustible & Inert \\
\hline Autumn & 0.12 & -0.83 & 0.00 & 0.06 & 0.05 & -0.03 & 0.15 & -0.15 & -0.15 \\
Winter & -0.12 & -0.56 & 0.01 & -0.17 & -0.18 & 0.11 & -0.04 & 0.12 & 0.43 \\
Summer & 0.00 & 1.39 & 0.00 & 0.11 & 0.13 & -0.08 & -0.12 & 0.02 & -0.28 \\
\hline
\end{tabular}

SM Table 4: Results of back-transformation of log of the ration between geometric mean of subgroups and the average geometric mean. Subgroups are seasons. These estimates were computed using Eq. 3 and correspond to the values of $\boldsymbol{k}$

\begin{tabular}{lccccccccc}
\hline Seasons & Food & Garden & Paper & Board & Plastic & Plastic foil & Metal & Combustible & Inert \\
\hline Autumn & 1.12 & 0.43 & 1.00 & 1.07 & 1.05 & 0.97 & 1.16 & 0.86 & 0.86 \\
Winter & 0.89 & 0.57 & 1.01 & 0.84 & 0.84 & 1.11 & 0.96 & 1.13 & 1.53 \\
Summer & 1.00 & 4.03 & 1.00 & 1.11 & 1.14 & 0.92 & 0.89 & 1.02 & 0.76 \\
\hline
\end{tabular}


SM Table 5: Results of back-transformation of log of the ration between geometric mean of subgroups and the average geometric mean. Subgroups are seasons. These estimates were computed using Eq. 3 and correspond to the values of $\boldsymbol{r}$ in percentage

\begin{tabular}{lcccccccccc}
\hline Seasons & Food & Garden & Paper & Board & Plastic & Plastic foil & Metal & Combustible & Inert \\
\hline Autumn & 12 & -57 & 0 & 7 & 5 & -3 & 16 & -14 & -14 \\
Winter & -11 & -43 & 1 & -16 & -16 & 11 & -4 & 13 & 53 \\
Summer & 0 & 303 & 0 & 11 & 14 & -8 & -11 & 2 & -24 \\
\hline
\end{tabular}

SM Table 6: Results of log of the ration between geometric mean of subgroups and the average geometric mean. Subgroups are household sizes. These estimates were computed using Eq. 2 and correspond to the values of $\boldsymbol{X}$

\begin{tabular}{lccccccccc}
\hline Household sizes & Food & Garden & Paper & Board & Plastic & Plastic foil & Metal & Combustible & Inert \\
\hline $1 \mathrm{p}$ & 20.29 & 0.01 & 10.99 & 6.82 & 1.91 & 3.98 & 0.52 & 12.39 & 0.00 \\
$2 \mathrm{p}$ & 37.62 & 0.04 & 8.58 & 6.10 & 3.34 & 5.82 & 0.91 & 9.74 & 0.01 \\
$3 \mathrm{p}$ & 41.90 & 0.06 & 10.48 & 4.43 & 4.09 & 5.99 & 1.13 & 7.07 & 0.04 \\
$4 \mathrm{p}$ & 40.98 & 0.01 & 7.56 & 7.05 & 4.65 & 4.29 & 0.75 & 9.75 & 0.01 \\
Total average & 35.64 & 0.02 & 8.82 & 6.20 & 3.46 & 5.07 & 0.82 & 9.69 & 0.01 \\
\hline
\end{tabular}

SM Table 7: Results of log of the ration between geometric mean of subgroups and the average geometric mean. Subgroups are household sizes. These estimates were computed using Eq. 2 and correspond to the values of $\boldsymbol{X}$

\begin{tabular}{lccccccccc}
\hline Household sizes & Food & Garden & Paper & Board & Plastic & Plastic foil & Metal & Combustible & Inert \\
\hline $1 \mathrm{p}$ & -0.56 & -1.26 & 0.22 & 0.1 & -0.59 & -0.24 & -0.44 & 0.25 & -1.28 \\
$2 \mathrm{p}$ & 0.05 & 0.58 & -0.03 & -0.02 & -0.03 & 0.14 & 0.11 & 0 & 0.17 \\
$3 \mathrm{p}$ & 0.16 & 0.94 & 0.17 & -0.33 & 0.17 & 0.17 & 0.33 & -0.32 & 1.09 \\
$4 \mathrm{p}$ & 0.14 & -0.7 & -0.15 & 0.13 & 0.3 & -0.17 & -0.09 & 0.01 & -0.09 \\
\hline
\end{tabular}

SM Table 8: Results of back-transformation of log of the ratio between geometric mean of subgroups and the average geometric mean. Subgroups are household sizes. These estimates were computed using Eq. 3 and correspond to the values of $\boldsymbol{k}$

\begin{tabular}{lccccccccc}
\hline Households sizes & Food & Garden & Paper & Board & Plastic & Plastic foil & Metal & Combustible & Inert \\
\hline $1 \mathrm{p}$ & 0.57 & 0.28 & 1.25 & 1.10 & 0.55 & 0.78 & 0.64 & 1.28 & 0.28 \\
$2 \mathrm{p}$ & 1.06 & 1.79 & 0.97 & 0.98 & 0.97 & 1.15 & 1.12 & 1.00 & 1.18 \\
$3 \mathrm{p}$ & 1.18 & 2.55 & 1.19 & 0.72 & 1.18 & 1.18 & 1.39 & 0.73 & 2.99 \\
$4 \mathrm{p}$ & 1.15 & 0.50 & 0.86 & 1.14 & 1.34 & 0.85 & 0.91 & 1.01 & 0.91 \\
\hline
\end{tabular}


SM Table 9: Results of back-transformation of log of the ratio between geometric mean of subgroups and the average geometric mean. Subgroups are household sizes. These estimates were computed using Eq. 3 and correspond to the values of $\boldsymbol{r}$ in percentage

\begin{tabular}{lccccccccc}
\hline Households sizes & Food & Garden & Paper & Board & Plastic & Plastic foil & Metal & Combustible & Inert \\
\hline $1 \mathrm{p}$ & -43 & -72 & 25 & 10 & -45 & -22 & -36 & 28 & -72 \\
$2 \mathrm{p}$ & 6 & 79 & -3 & -2 & -3 & 15 & 12 & 0 & 18 \\
$3 \mathrm{p}$ & 18 & 155 & 19 & -28 & 18 & 18 & 39 & -27 & 199 \\
$4 \mathrm{p}$ & 15 & -50 & -14 & 14 & 34 & -15 & -9 & 1 & -9 \\
\hline
\end{tabular}




\section{Pairwise and individual comparison of residual household waste composition between household types:}

Here, "original" is the original estimate of the difference between household types for each waste fraction whereas "std. error" is the standard errors or the uncertainty associated to the estimates. "Basic" and "BCA" are the type of confidence intervals returned from bootstrap.

SM Table 10.1a: 1person and 2 persons: Bootstrap statistics

\begin{tabular}{lccc}
\hline \multicolumn{1}{c}{ Waste fractions } & original & bias & std. error \\
\hline Food & 0.380 & 0.014 & 0.198 \\
Garden & 1.600 & 0.022 & 1.148 \\
Paper & -0.486 & 0.031 & 0.334 \\
Board & -0.350 & 0.027 & 0.170 \\
Plastic & 0.323 & 0.010 & 0.366 \\
Plastic foil & 0.143 & 0.024 & 0.263 \\
Metal & 0.318 & 0.015 & 0.454 \\
Combustible & -0.478 & 0.024 & 0.202 \\
Inert & 1.210 & 0.048 & 1.226 \\
\hline
\end{tabular}

SM Table 10.1b: 1person and 2 persons: Bootstrap confidence intervals

\begin{tabular}{|c|c|c|c|c|c|c|c|c|c|}
\hline Basic & Food & Garden & Paper & Board & Plastic & Plastic foil & Metal & Combustible & Inert \\
\hline 1 person & -0.08 & -2.02 & -1.46 & -0.89 & -0.70 & -0.52 & -0.88 & -1.17 & -2.67 \\
\hline 2 persons & 1.3885 & 5.50 & 0.73 & 0.27 & 1.71 & 1.28 & 2.25 & 0.14 & 5.20 \\
\hline BCA & Food & Garden & Paper & Board & Plastic & Plastic foil & Metal & Combustible & Inert \\
\hline 1 person & -0.05 & -2.02 & -1.46 & -0.89 & -0.70 & -0.48 & -0.88 & -1.17 & -2.67 \\
\hline 2 persons & 1.38 & 5.50 & 0.73 & 0.14 & 1.71 & 1.28 & 2.22 & 0.14 & 5.20 \\
\hline
\end{tabular}

SM Table 10.2a: 1person and 3 persons: Bootstrap statistics

\begin{tabular}{lccc}
\hline \multicolumn{1}{c}{ Waste fractions } & original & bias & std. error \\
\hline Food & 0.45 & 0.02 & 0.20 \\
Garden & 1.92 & 0.05 & 1.50 \\
Paper & -0.33 & 0.02 & 0.36 \\
Board & -0.71 & 0.02 & 0.27 \\
Plastic & 0.48 & 0.01 & 0.36 \\
Plastic foil & 0.13 & 0.01 & 0.27 \\
Metal & 0.49 & 0.01 & 0.50 \\
Combustible & -0.84 & 0.02 & 0.22 \\
Inert & 2.09 & -0.03 & 1.53 \\
\hline
\end{tabular}

SM Table 10.2b: 1person and 3 persons: Bootstrap confidence intervals

\begin{tabular}{|c|c|c|c|c|c|c|c|c|c|c|}
\hline BASIC & Food & & Garden & Paper & Board & Plastic & Plastic foil & Metal & Combustible & Inert \\
\hline 1 person & & 0.02 & -2.59 & $\begin{array}{l}-1.33 \\
\end{array}$ & -2.37 & -0.51 & $\begin{array}{l}-0.44 \\
\end{array}$ & -1.30 & $\begin{array}{l}-1.46 \\
\end{array}$ & -2.59 \\
\hline 3 persons & & 1.31 & 6.52 & 1.21 & 0.07 & 1.94 & 1.13 & 2.21 & -0.06 & 7.20 \\
\hline $\mathrm{BCA}$ & Food & & Garden & Paper & Board & Plastic & Plastic foil & Metal & Combustible & Inert \\
\hline 1 person & & 0.09 & -2.59 & -1.12 & -2.37 & -0.41 & -0.37 & -1.30 & $\begin{array}{l}-1.46 \\
\end{array}$ & -2.59 \\
\hline 3 persons & & 1.31 & 6.52 & 1.21 & -0.20 & 1.94 & 1.13 & 2.21 & -0.19 & 7.20 \\
\hline
\end{tabular}

SM Table 10.3a: 1person and 4 persons: Bootstrap statistics

\begin{tabular}{lccc}
\hline \multicolumn{1}{c}{ Waste fractions } & original & bias & std. error \\
\hline Food & 0.43 & 0.01 & 0.20 \\
Garden & 0.28 & -0.05 & 1.28 \\
Paper & -0.65 & 0.02 & 0.34 \\
Board & -0.24 & 0.03 & 0.16 \\
Plastic & 0.61 & 0.02 & 0.37 \\
Plastic foil & -0.20 & 0.04 & 0.35 \\
Metal & 0.08 & 0.01 & 0.49 \\
Combustible & -0.52 & 0.04 & 0.21 \\
Inert & 0.91 & 0.02 & 1.32 \\
\hline
\end{tabular}


SM Table 10.3b: 1person and 4 persons: Bootstrap confidence intervals

\begin{tabular}{|c|c|c|c|c|c|c|c|c|c|}
\hline Basic & Food & Garden & Paper & Board & Plastic & Plastic foil & Metal & Combustible & Inert \\
\hline 1 person & -0.09 & -4.26 & -1.39 & -0.76 & -0.26 & -1.20 & -1.86 & -1.15 & -3.19 \\
\hline 4 persons & 1.28 & 4.32 & 0.67 & 0.28 & 1.84 & 1.02 & 2.06 & 0.12 & 5.80 \\
\hline BCA & Food & Garden & Paper & Board & Plastic & Plastic foil & Metal & Combustible & Inert \\
\hline 1 person & 0.02 & -4.26 & -1.34 & -0.76 & -0.24 & -1.20 & -1.86 & -1.15 & -3.19 \\
\hline 4 persons & 1.28 & 4.32 & 0.67 & 0.22 & 1.84 & 0.90 & 2.06 & 0.09 & 5.80 \\
\hline
\end{tabular}

SM Table 10.4a: 2person and 3 persons: Bootstrap statistics

\begin{tabular}{lccc}
\hline \multicolumn{1}{c}{ Waste fractions } & original & bias & std. error \\
\hline Food & 0.07 & 0.00 & 0.07 \\
Garden & 0.32 & 0.06 & 1.24 \\
Paper & 0.16 & 0.00 & 0.20 \\
Board & -0.36 & -0.02 & 0.28 \\
Plastic & 0.16 & 0.00 & 0.14 \\
Plastic foil & -0.01 & 0.00 & 0.12 \\
Metal & 0.17 & -0.01 & 0.34 \\
Combustible & -0.36 & 0.00 & 0.15 \\
Inert & 0.89 & -0.05 & 1.33 \\
\hline
\end{tabular}

SM Table 10.4b: 2person and 3 persons: Bootstrap confidence intervals

\begin{tabular}{|c|c|c|c|c|c|c|c|c|c|}
\hline Basic & Food & Garden & Paper & Board & Plastic & Plastic foil & Metal & Combustible & Inert \\
\hline 2 person & -0.13 & -3.15 & -0.62 & -1.81 & -0.30 & -0.44 & -1.20 & -1.00 & -3.95 \\
\hline 3 persons & 0.33 & 4.02 & 0.70 & 0.40 & 0.63 & 0.35 & 1.23 & 0.16 & 4.64 \\
\hline BCA & Food & Garden & Paper & Board & Plastic & Plastic foil & Metal & Combustible & Inert \\
\hline 2 person & -0.12 & -3.15 & -0.60 & -1.81 & -0.26 & -0.43 & -1.18 & -1.00 & -3.95 \\
\hline 3 persons & 0.33 & 4.02 & 0.70 & 0.40 & 0.63 & 0.35 & 1.23 & 0.16 & 4.64 \\
\hline
\end{tabular}

SM Table 10.5a: 2person and 4 persons: Bootstrap statistics

\begin{tabular}{lccc}
\hline Waste fractions & original & bias & std. error \\
\hline Food & 0.046 & -0.01 & 0.07 \\
Garden & -1.32 & 0.04 & 0.94 \\
Paper & -0.17 & 0.01 & 0.15 \\
Board & 0.11 & 0.01 & 0.17 \\
Plastic & 0.29 & 0.00 & 0.15 \\
Plastic foil & -0.34 & 0.00 & 0.24 \\
Metal & -0.24 & 0.01 & 0.35 \\
Combustible & -0.04 & 0.00 & 0.15 \\
Inert & -0.30 & 0.02 & 1.03 \\
\hline
\end{tabular}

SM Table 10.5b: 2person and 4 persons: Bootstrap confidence intervals

\begin{tabular}{|c|c|c|c|c|c|c|c|c|c|}
\hline BASIC & Food & Garden & Paper & Board & Plastic & Plastic foil & Metal & Combustible & Inert \\
\hline 2 person & -0.23 & -4.39 & -0.61 & -0.36 & -0.14 & -1.30 & -1.51 & -0.54 & -3.47 \\
\hline 4 persons & 0.33 & 1.68 & 0.32 & 0.59 & 0.88 & 0.25 & 0.89 & 0.46 & 2.91 \\
\hline BCA & Food & Garden & Paper & Board & Plastic & Plastic foil & Metal & Combustible & Inert \\
\hline 2 person & -0.16 & -4.39 & -0.61 & -0.36 & -0.12 & $\begin{array}{l}-1.30 \\
\end{array}$ & -1.51 & -0.54 & -3.47 \\
\hline 4persons & 0.33 & 1.68 & 0.32 & 0.59 & 0.88 & 0.23 & 0.89 & 0.46 & 2.91 \\
\hline
\end{tabular}

SM Table 10.6a: 3person and 4 persons: Bootstrap statistics 


\begin{tabular}{lccc}
\hline \multicolumn{1}{c}{ Waste fractions } & original & bias & std. error \\
\hline Food & -0.02040475 & 0.000249109 & 0.06785177 \\
Garden & -1.63 & -0.07 & 1.34 \\
Paper & -0.33 & 0.00 & 0.18 \\
Board & 0.47 & 0.00 & 0.26 \\
Plastic & 0.13 & 0.01 & 0.14 \\
Plastic foil & -0.33 & -0.01 & 0.27 \\
Metal & -0.42 & -0.01 & 0.43 \\
Combustible & 0.32 & 0.00 & 0.16 \\
Inert & -1.19 & -0.08 & 1.34 \\
\hline
\end{tabular}

SM Table 10.5b: 2person and 4 persons: Bootstrap confidence intervals

\begin{tabular}{|c|c|c|c|c|c|c|c|c|c|}
\hline BASIC & Food & Garden & Paper & Board & Plastic & Plastic foil & Metal & Combustible & Inert \\
\hline 3 person & -0.26 & -5.52 & -0.87 & -0.07 & -0.33 & -1.43 & -1.79 & -0.14 & -5.31 \\
\hline 4persons & 0.18 & 3.42 & 0.42 & 1.53 & 0.56 & 0.29 & 1.09 & 0.92 & 2.34 \\
\hline$\$$ lim & bca & & & & & & & & \\
\hline BCA & Food & Garden & Paper & Board & Plastic & Plastic foil & Metal & Combustible & Inert \\
\hline 3 person & -0.26 & -5.52 & -0.87 & -0.05 & -0.33 & -1.43 & -1.79 & -0.14 & -5.31 \\
\hline 4persons & 0.18 & 3.42 & 0.42 & 1.53 & 0.52 & 0.24 & 1.09 & 0.92 & 2.34 \\
\hline
\end{tabular}

SM Table 11.A: Variation array for season: Winter, $\mathbf{N}=\mathbf{1 0 1}$

\begin{tabular}{|c|c|c|c|c|c|c|c|c|c|c|}
\hline \multirow[b]{2}{*}{$X i \backslash X j$} & \multicolumn{9}{|c|}{ Variance $\ln (\mathrm{Xi} / \mathrm{Xj})$} & \multirow[b]{2}{*}{ Clr variances } \\
\hline & Food & Garden & Paper & Board & Plastic & Plastic foil & Metal & Combustible & Inert & \\
\hline Food & & 2.3122 & 0.7788 & 0.4539 & 0.7631 & 0.4713 & 0.8269 & 0.8261 & 2.1608 & 0.4774 \\
\hline Garden & -3.102 & & 2.0235 & 1.8036 & 2.312 & 2.1085 & 1.6705 & 2.3019 & 3.5006 & 1.0018 \\
\hline Paper & -1.4962 & 1.6058 & & 0.657 & 1.0585 & 0.7266 & 0.8999 & 0.9842 & 2.1098 & 0.5132 \\
\hline Board & -1.9027 & 1.1994 & -0.4065 & & 0.6603 & 0.4321 & 0.633 & 0.5882 & 2.0169 & 0.4025 \\
\hline Plastic & -2.3895 & 0.7125 & -0.8933 & -0.4868 & & 0.6443 & 0.825 & 1.0225 & 2.3439 & 0.535 \\
\hline Plastic foil & -2.0273 & 1.0748 & -0.5311 & -0.1246 & 0.3622 & & 0.709 & 0.5154 & 2.3702 & 0.4432 \\
\hline Metal & -3.1205 & -0.0185 & -1.6243 & -1.2179 & -0.731 & -1.0933 & & 1.4412 & 2.5408 & 0.5304 \\
\hline Combustible & -1.8135 & 1.2886 & -0.3172 & 0.0892 & 0.5761 & 0.2138 & 1.3071 & & 2.5286 & 0.5671 \\
\hline Inert & -2.4951 & 0.6069 & -0.9989 & -0.5924 & -0.1056 & -0.4679 & 0.6254 & -0.6817 & & 1.0873 \\
\hline \multicolumn{4}{|c|}{ Mean $\ln (\mathrm{Xi} / \mathrm{Xj})$} & & & & & & & 5.5579 \\
\hline
\end{tabular}

SM Table 11.B: Variation array for season: Autumn, $\mathbf{N}=\mathbf{1 0 1}$

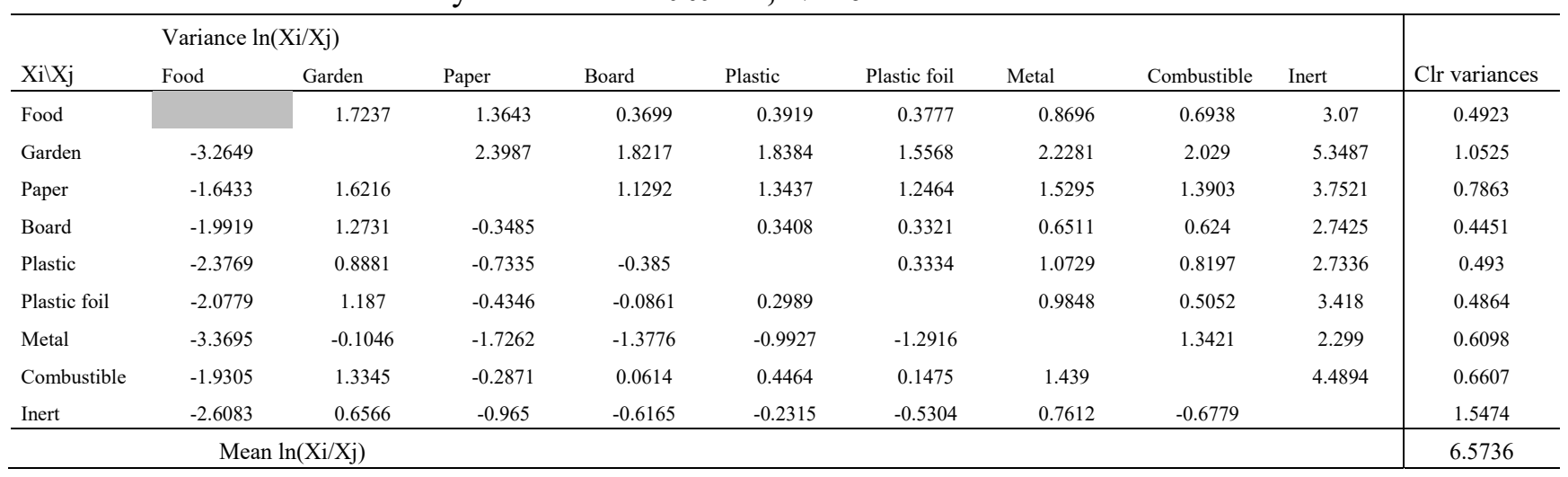


SM Table 11.C: Variation array for season: Summer, $\mathbf{N}=\mathbf{1 0 1}$

\begin{tabular}{|c|c|c|c|c|c|c|c|c|c|c|}
\hline \multirow[b]{2}{*}{$\mathrm{Xi} \backslash \mathrm{Xj}$} & \multicolumn{9}{|c|}{ Variance $\ln (\mathrm{Xi} / \mathrm{Xj})$} & \multirow[b]{2}{*}{ Clr variances } \\
\hline & Food & Garden & Paper & Board & Plastic & Plastic foil & Metal & Combustible & Inert & \\
\hline Food & & 2.5496 & 1.3551 & 0.6426 & 0.5619 & 0.3429 & 0.8165 & 0.5624 & 2.1512 & 0.499 \\
\hline Garden & -3.1419 & & 2.9087 & 2.8185 & 3.2011 & 2.3028 & 3.8761 & 2.4951 & 3.2275 & 1.2989 \\
\hline Paper & -1.1522 & 1.9897 & & 1.1705 & 1.8249 & 0.7816 & 2.4114 & 1.3171 & 1.9662 & 0.7631 \\
\hline Board & -1.7331 & 1.4088 & -0.5809 & & 0.6693 & 0.2591 & 1.4926 & 0.5739 & 2.2722 & 0.5499 \\
\hline Plastic & -2.3672 & 0.7747 & -1.215 & -0.6341 & & 0.502 & 0.8872 & 0.7174 & 2.5108 & 0.6041 \\
\hline Plastic foil & -1.7743 & 1.3677 & -0.6221 & -0.0412 & 0.593 & & 1.0963 & 0.349 & 1.6368 & 0.4039 \\
\hline Metal & -2.9515 & 0.1904 & -1.7993 & -1.2184 & -0.5843 & -1.1772 & & 1.2514 & 2.7415 & 0.8096 \\
\hline Combustible & -1.5109 & 1.631 & -0.3588 & 0.2221 & 0.8563 & 0.2633 & 1.4406 & & 2.0055 & 0.5151 \\
\hline Inert & -2.4826 & 0.6593 & -1.3304 & -0.7495 & -0.1154 & -0.7083 & 0.4689 & -0.9717 & & 1.0284 \\
\hline \multicolumn{4}{|c|}{ Mean $\ln (\mathrm{Xi} / \mathrm{Xj})$} & & & & & & & 6.4721 \\
\hline
\end{tabular}




\section{Supplementary data (SM) -Figures}

SM Figure 1: Boxplot showing the waste generation rates (a) $\mathrm{kg} / \mathrm{household} /$ week and (b) $\mathrm{kg} /$ person/week as function of seasons (autumn, summer and winter).

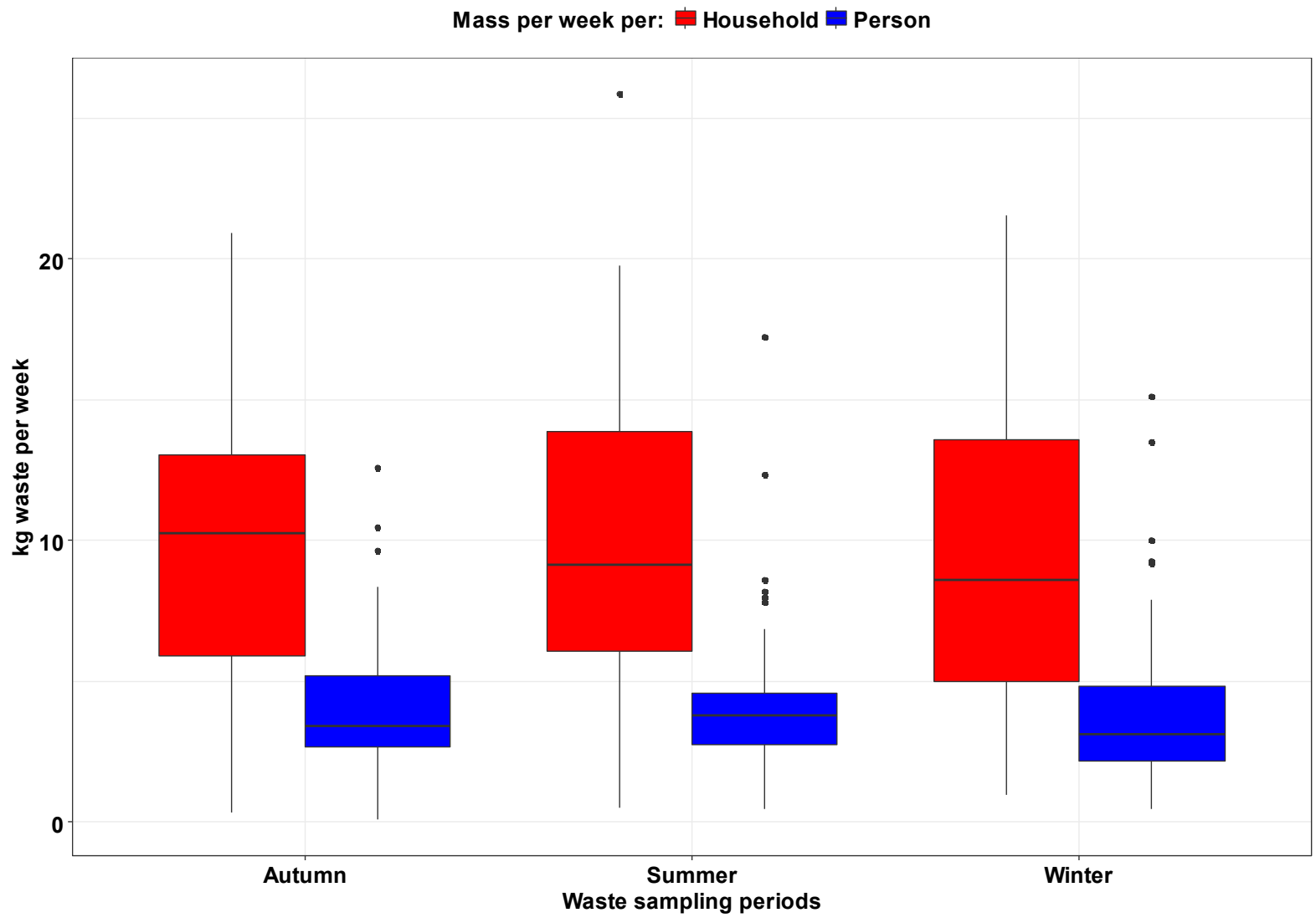


SM Figure 2: Boxplot showing the means of waste generation rates as function of household sizes.
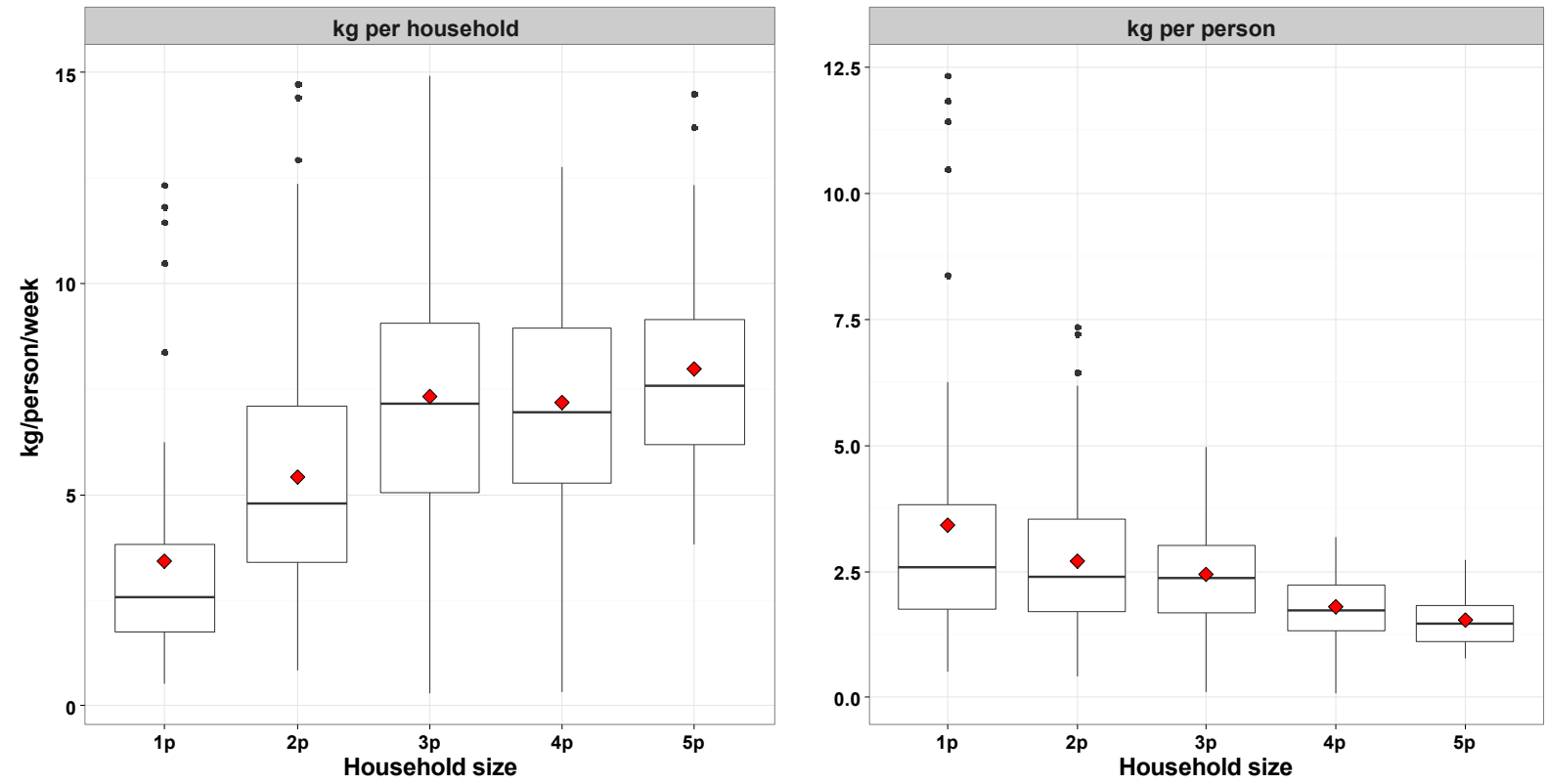
SM Figure 3: Boxplots showing waste generates according to season as functions of households size:household containing one (1p), to $(2 p)$, tree $(3 p)$ and more than tree $(3 p)$ persons.

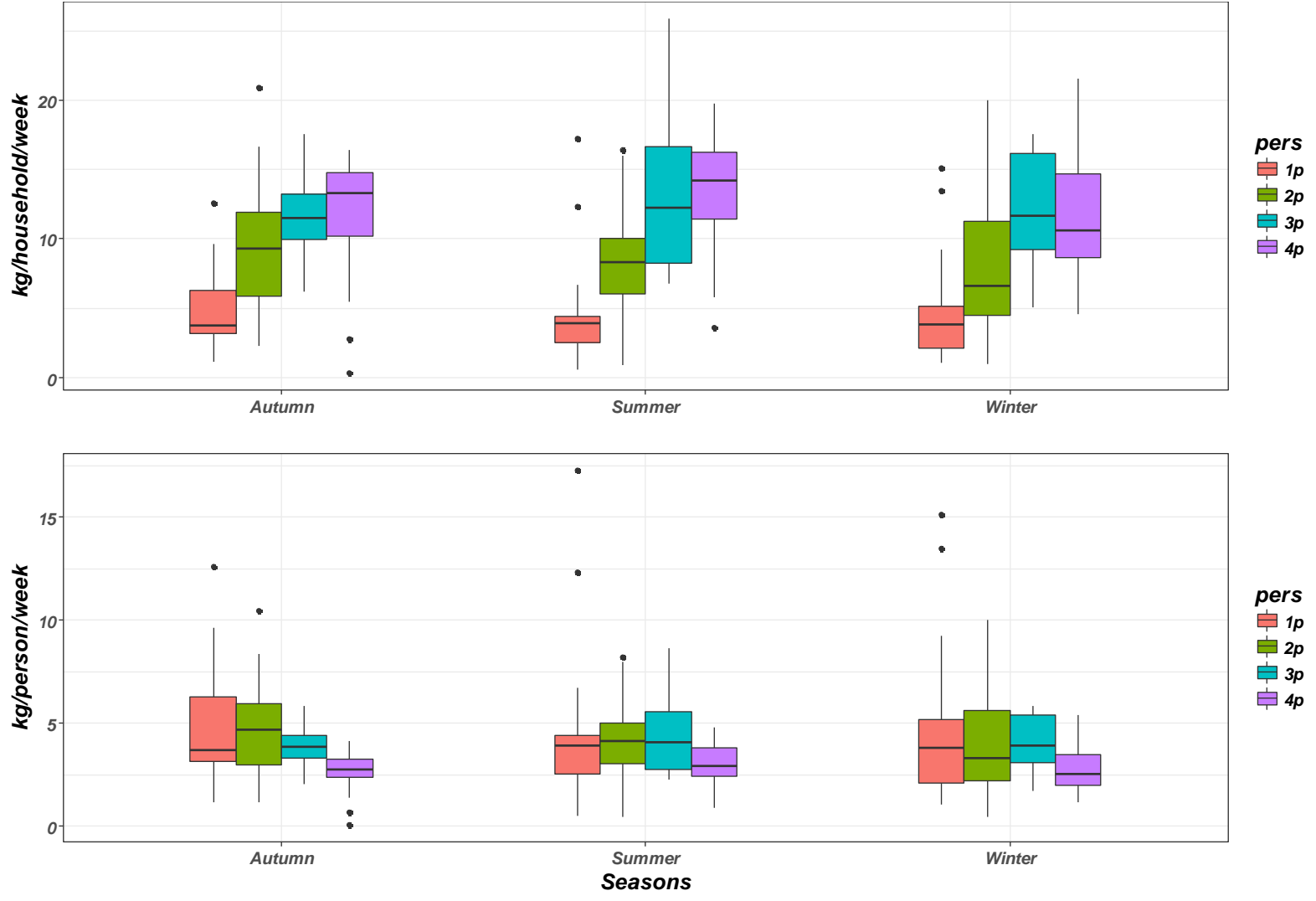


SM Figure 4: 95\% prediction interval on the random effects in waste generation rate per person (kg/person/week).Horizontal lines represent the mean and 95\% confidence intervals of 101 households.

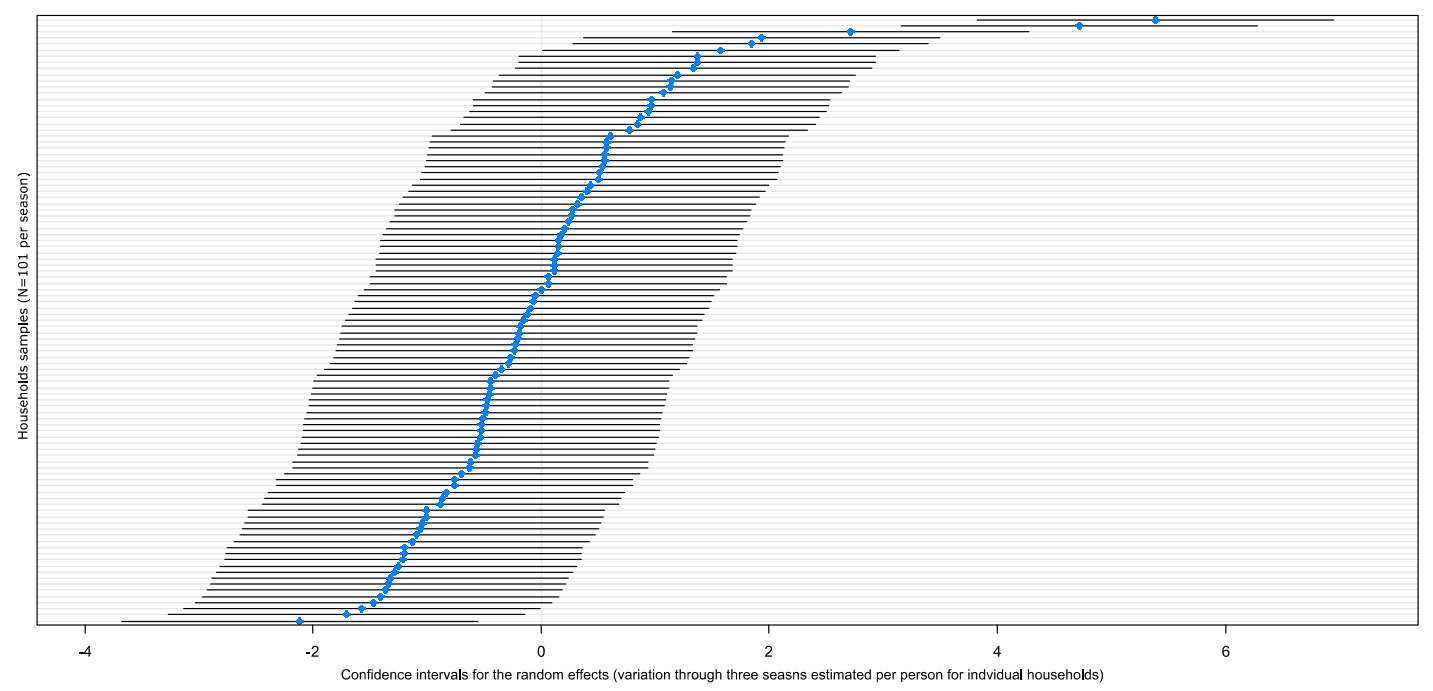


SM Figure 5: Boxplots showing waste generates according to household size (household containing one (1p), to (2p), tree (3p) and more than tree (3p) persons) as function of seasons (automn, summer and winter).

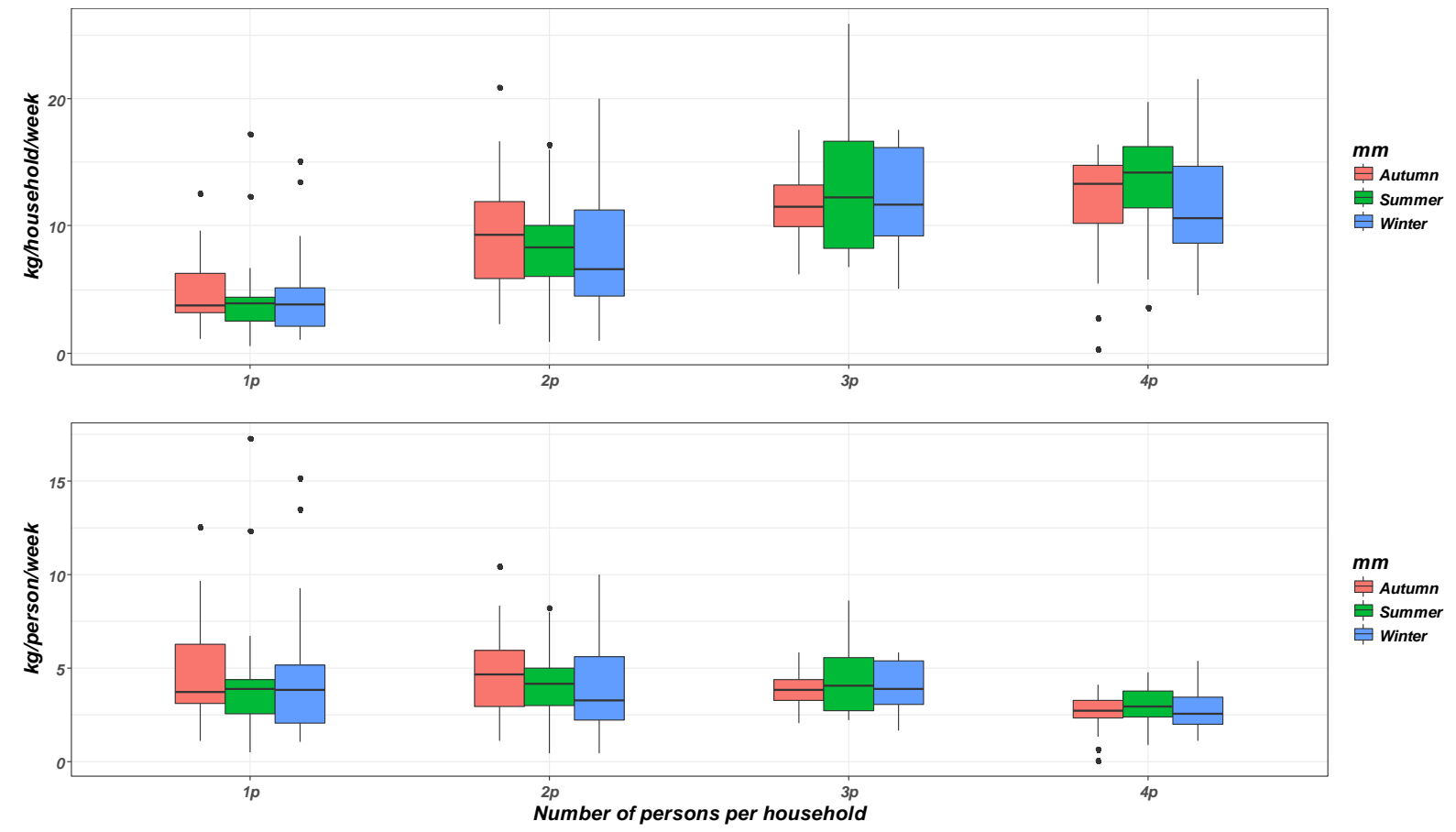



SM Figure 6: Illustration of linear mixed model result for waste generation rate (dataset of $\mathrm{kg} /$ household/week): results of the contribution of (a) season, (b) interaction seasons and person as well as random effect, and (c) household sizes

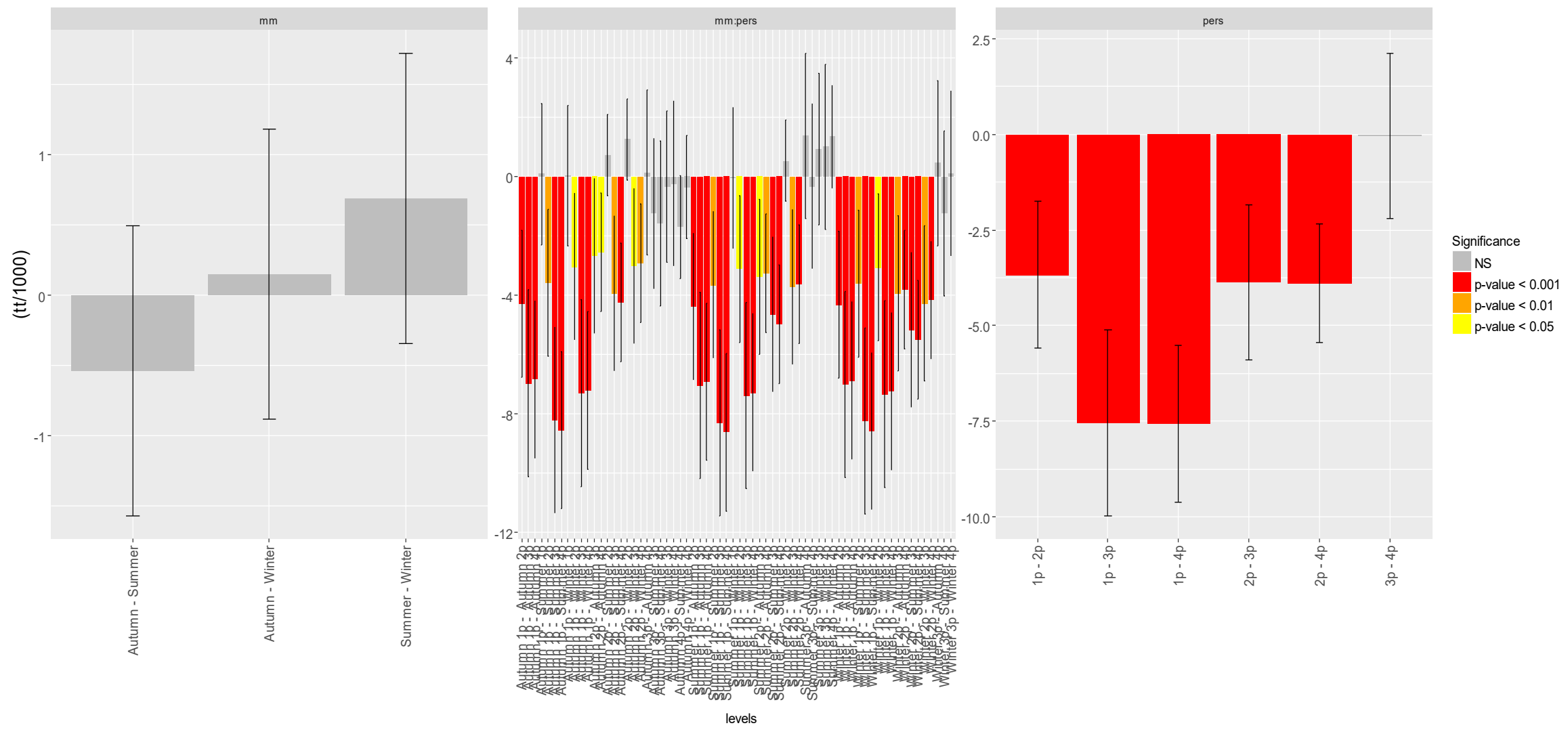


SM Figure 7: Illustration of linear mixed model result for waste generation rate (dataset of $\mathrm{kg} / \mathrm{person} / \mathrm{week}$ ): results of the contribution of (a) season, (b) interaction seasons and person as well as random effect, and (c) household sizes

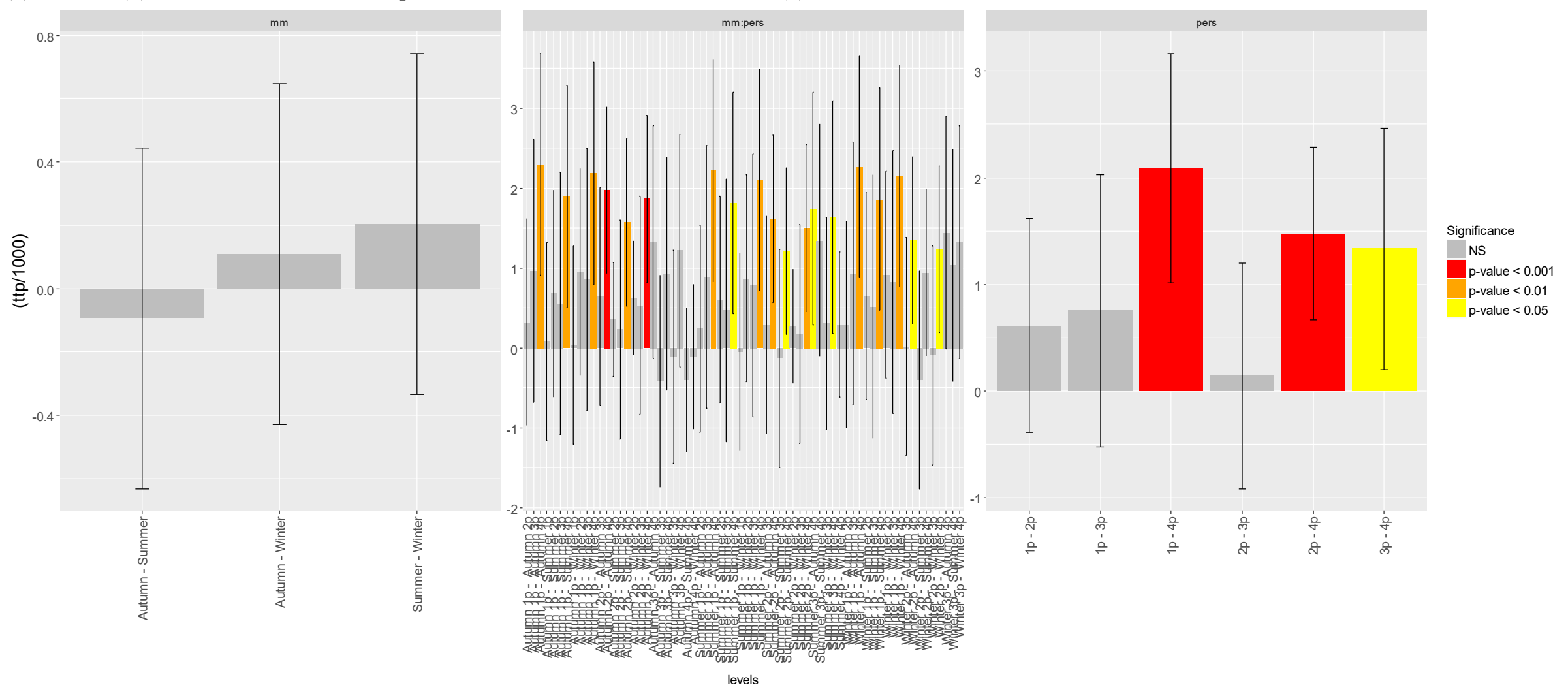


SM Figure 8: Results of linear mixed model applied to isometric log-ratio: results of the contribution of (a) season, (b) interaction seasons and person as well as random effect, and (c) household sizes

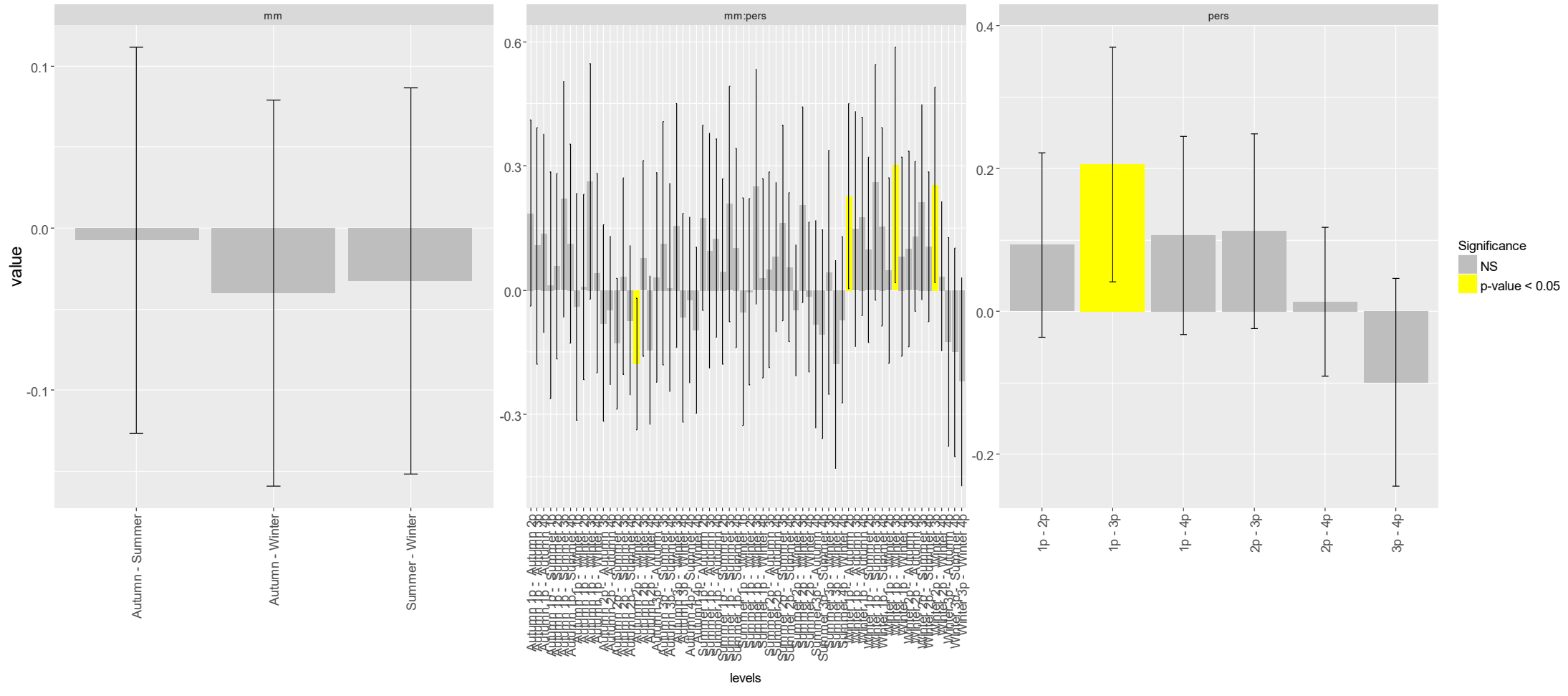


SM Figure 9: Diagnostic plot for the linear mixed model determining any influence of seasonal variation and household size on the waste generation, dataset of $\mathrm{kg} /$ household/week
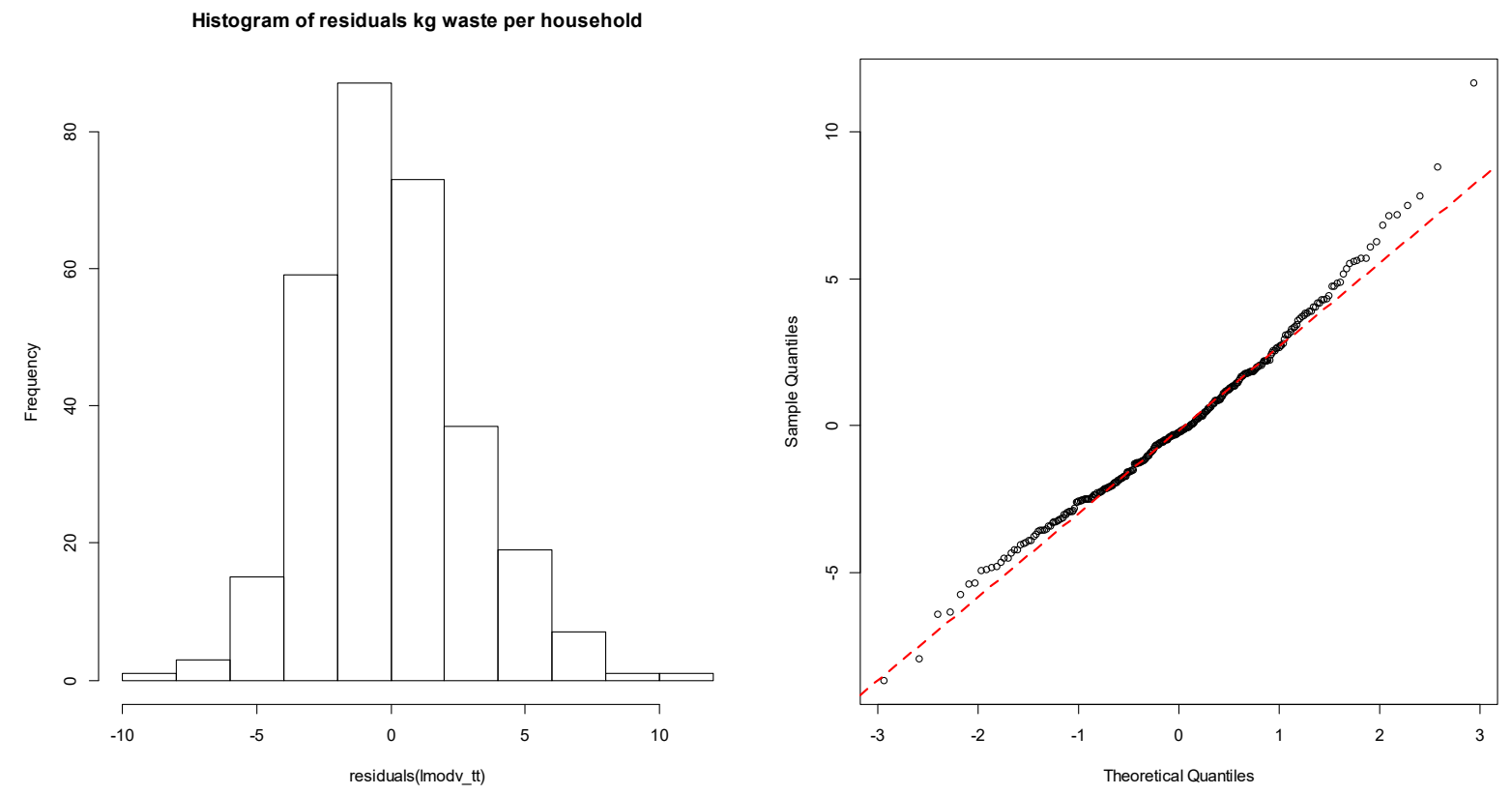

SM Figure 10: Diagnostic plot for the linear mixed model determining any influence of seasonal variation and household size on the waste generation, dataset of $\mathrm{kg} /$ person/week

Histogram of residuals $\mathbf{k g}$ waste per person
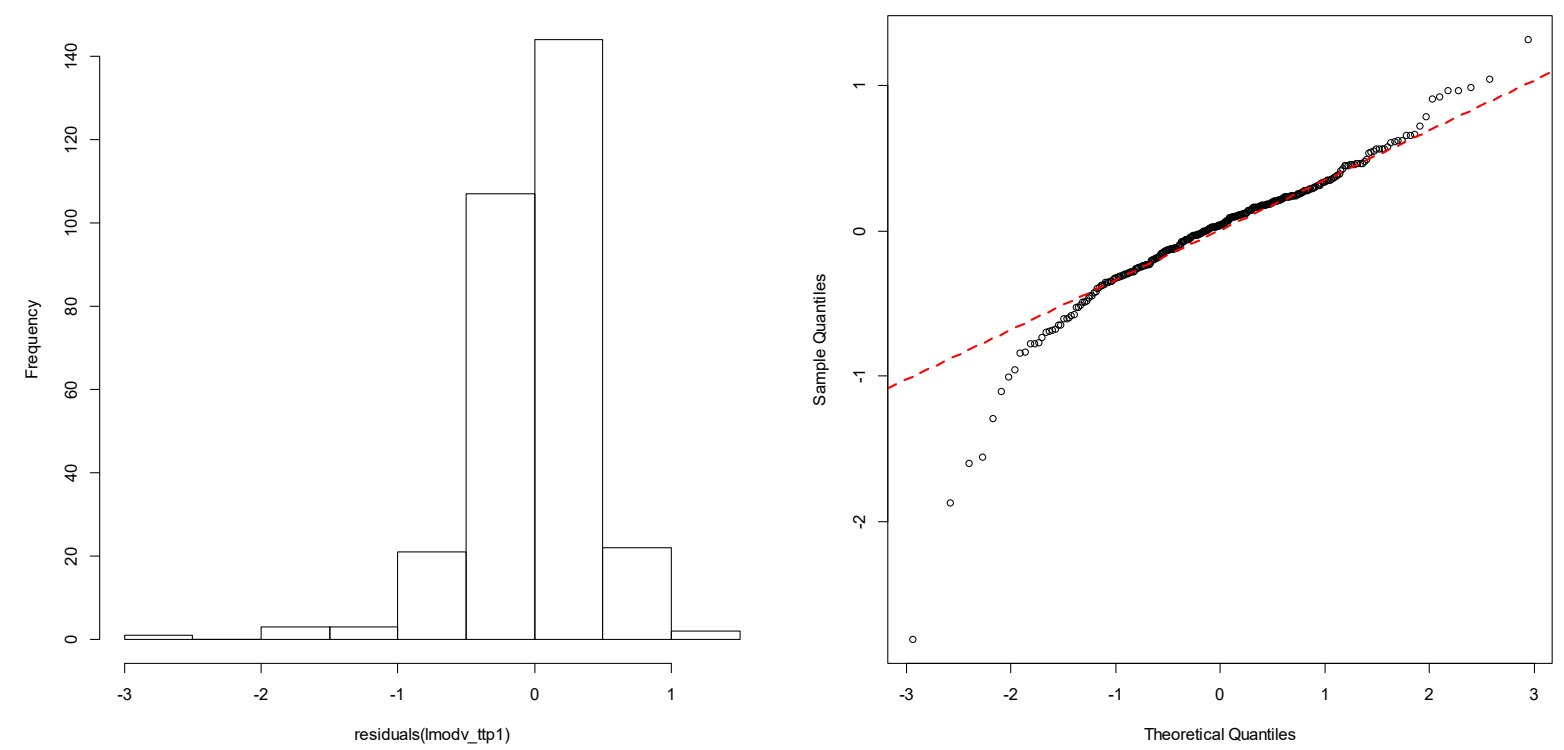
SM Figure 11: Diagnostic plot for multivariate normality based on qqplot of residuals
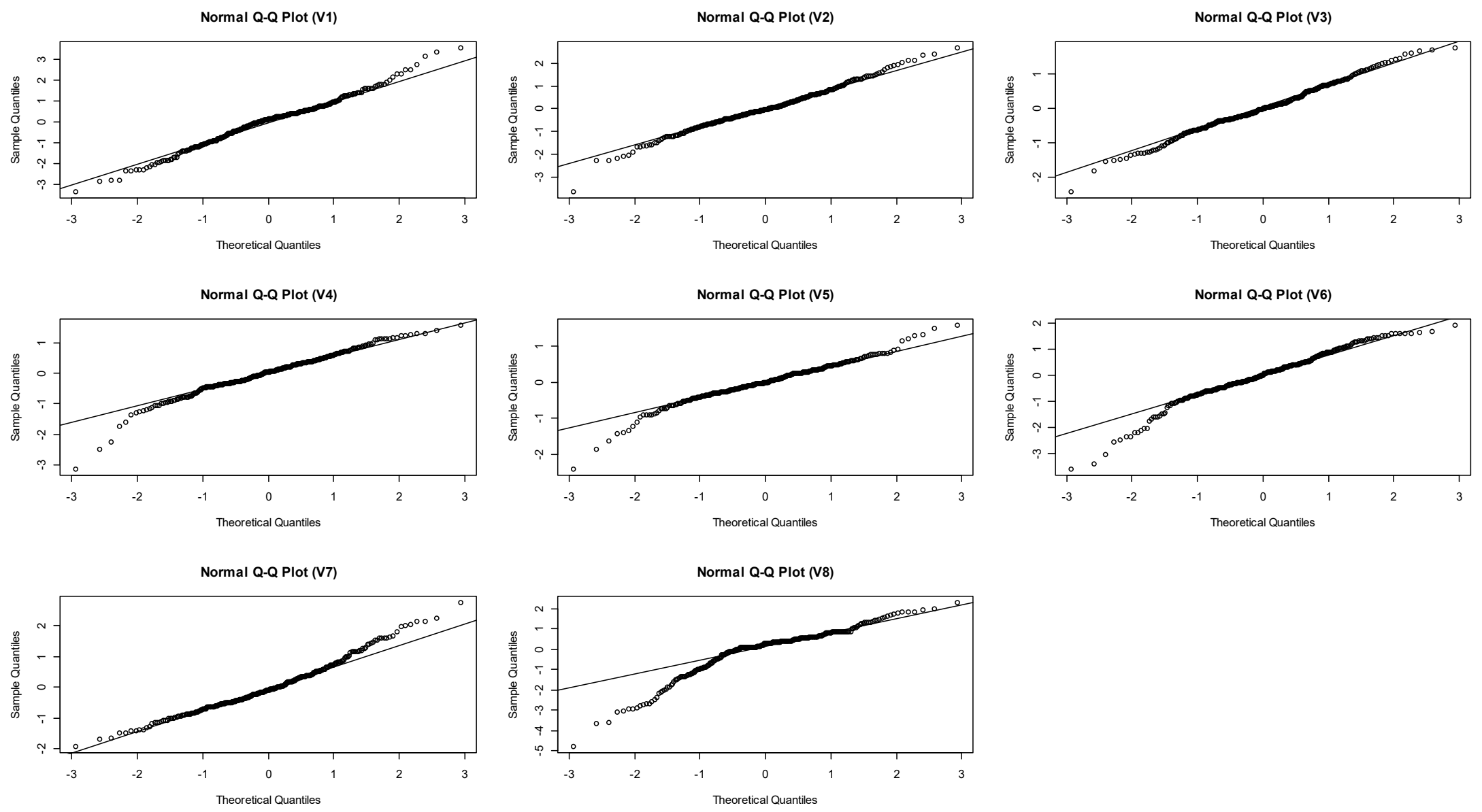
SM Figure 12: Diagnostic plot for multivariate normality of residuals based on histogram of residuals and boxplot of raw isometric log coordinates
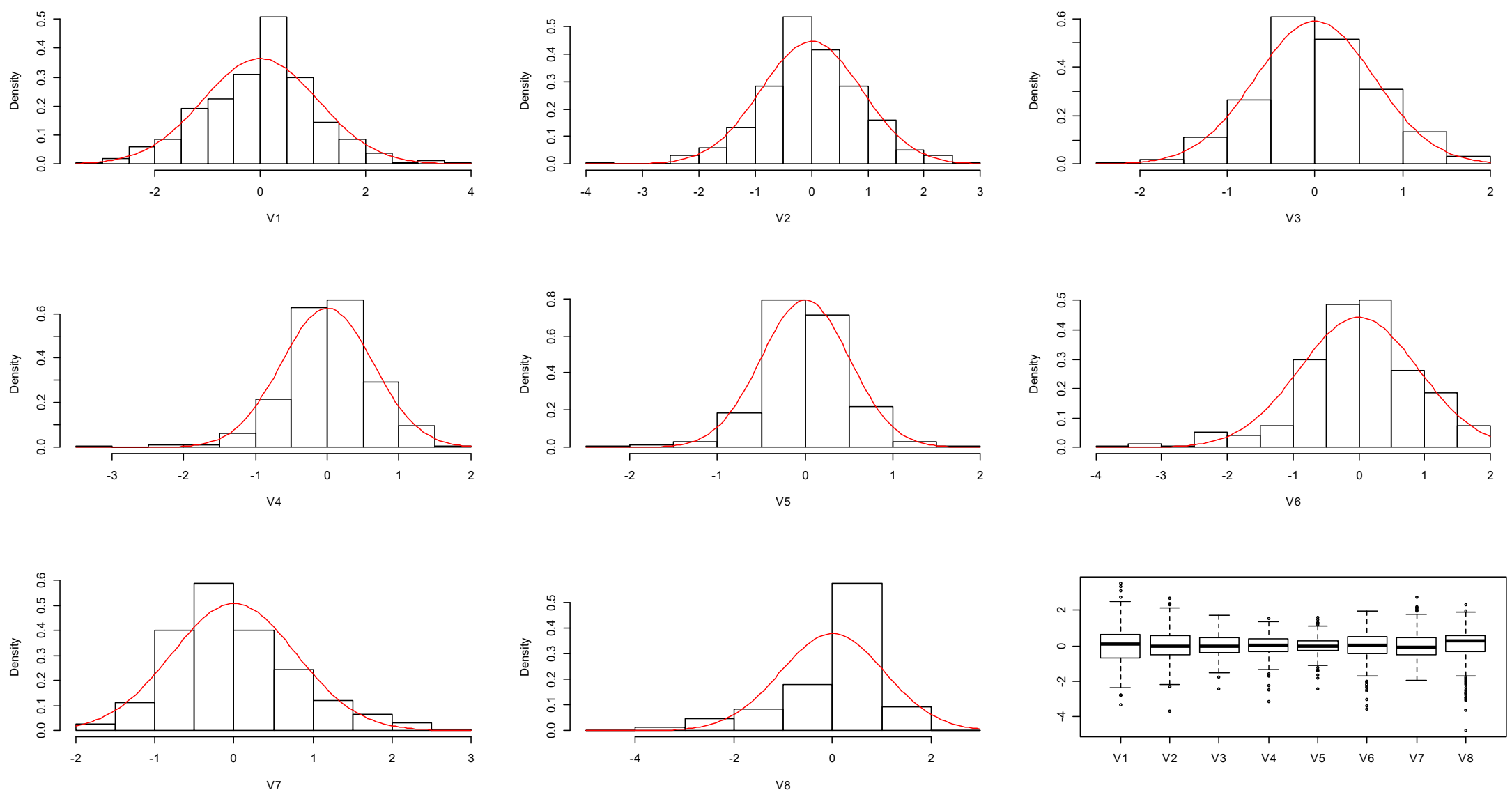